\title{
Media, Protest and Resistance in Authoritarian Contexts
}

\author{
Layla M. Hashemi, Ph.D. \\ Public Policy \\ George Mason University, 2020 \\ lhashem2@gmu.edu \\ laymay.com
}

\begin{abstract}
Information communication technologies (ICTs) facilitate transnational connection, coordination and collaboration, which are essential for new social movements. At the same time, issues of access and censorship hinder social movement use of social media for mobilization. This paper examines how internet technology is used by social movements to discuss issues of identity, dignity and justice and to contest gender-based discriminatory laws. Through subtle everyday acts of protests, women contest state narratives by documenting their presence in both physical and virtual public spaces. Iranian women practice the art of presence, demonstrating social media activism's ability to circumvent censorship and facilitate public discourse regarding controversial issues under repressive contexts. This study collects and analyzes data from Twitter and other social networking platforms to investigate the evolution of digital campaigns and relates these cases to the long-standing tradition of Iranian women's voices with a focus on the critical role of the camera and user generated content in art and daily life.
\end{abstract}

Keywords: social movements; social media; internet studies; information communication technology; computational social science; Iran; gender; human rights

DRAFT WORKING PAPER Prepared for the Annual Meeting of the American Political Science Association, September 2020 
"Where there is power there is resistance"

- Michel Foucault

Information communication technologies (ICTs) facilitate transnational connection, coordination and collaboration, which are essential for new social movements. At the same time, issues of access and censorship hinder social movement use of social media for mobilization. This research examines how internet technology is used by the Iranian women's movements to discuss issues of identity, dignity and justice, and to contest gender-based discriminatory laws.

The Middle East has recently witnessed new relations between women and space where women have been empowered with new forms of social and physical mobility. Despite increased mobility, Iranian women continue to fight against the regime's gender discriminatory laws and protest the government in public squares and virtual spaces through subversive acts such as sneaking into soccer stadiums disguised as men. Using hashtags and other forms of cultural production, the movement against the gender discrimination highlights women's voices and presence. Contesting morality laws that exclude women from public space, hashtags such as \#bluegirl organize digital content and facilitate public discourse regarding issues of gender among Iranians and internationally. By documenting their unapologetic visibility in public spaces, Iranian women express their strength and resilience and continue a long tradition of media representation through cultural production and dissemination of information and iconic imagery on social media platforms.

Through subtle everyday acts of protests, women contest state narratives by documenting their presence in both physical and virtual public spaces. Iranian women practice the art of presence, demonstrating social media activism's ability to circumvent censorship and facilitate 
public discourse regarding controversial issues under repressive contexts. This research collects and analyzes original 2018 data from Twitter and other social networking platforms to investigate the evolution of digital campaigns and relates these cases to the long-standing tradition of Iranian women's voices with a focus on the role of the camera and user generated content in art and daily life.

This paper reveals the importance and power of imagery and media for mobilizing and organizing social movements in all contexts. The use of subtle protest and cultural production is particularly useful (or perhaps necessary) under repressive or circumstances. Though the study focuses on an authoritarian context, findings regarding the use of social media by social movements are generalizable and applicable to other cases. Even in authoritarian contexts, social movements leverage social media for cultural production, transnational connection and collaboration, gaining international attention and advancing movement objectives. Through strategic use of media and hashtags, movements are able to unify and rally members around common concerns or events and raise awareness of socio-economic issues that are often left unaddressed by formal political channels.

Through statistical and social network analysis (SNA), this study finds that specific content characteristics (media, hashtags and mentions of top users) significantly increase attention and engagement, allowing movement cultural production to reach a broader audience and remotely connect with activists (outside of the country). Women in the IRI and other countries have used platforms such as Twitter to (re)claim their right to public space and continue their plight for gender equality despite the tremendous risks of dissent in the highly repressive environments which they inhabit. 
ICT has long been used as a medium of expression, rebellion, or resistance. Social media has changed the way individuals and groups express and discuss political opinions. In an era of digital diplomacy, it is important to consider the impact of new forms of communication on domestic and international politics. New media has impacted the way social movements are established and arguably plays an even larger role in how these phenomena evolve. Through a digital ethnography of the women's movement in the Islamic Republic of Iran (IRI), this paper examines how ICT is used by social movements as a form of circumventing censorship and repression in authoritarian contexts by examining several Iranian women's movement (IWM) in the Islamic Republic of Iran (IRI) and the networks involved in propagating related digital campaigns.

Social media analytics and computational social science are nascent fields offering tremendous possibilities for social scientists. This paper contributes to existing research in the field by providing robust methods and models of communication networks that can help inform internet governance and regulatory policies. While many scholars of new social movements focus on the establishment and evolution of movements in Western contexts, this research contributes to new social movement literature by analyzing a non-Western, Middle Eastern case of new social movements. The analysis of online public discourse helps explain how individuals and groups form identities and collectives, contributing not only to the existing social movement literature but also informing the related fields of media and communication, computer science and gender studies.

2020 marks the 20th anniversary of United Nations Security Council Resolution 1325 which launched the Women in Peace and Security (WPS) agenda and the 25th anniversary of the 
Beijing Declaration. While efforts to promote gender equality have benefited from advances in policy and developments in technology, there is still much to be done to achieve UN Sustainable Development Goal (SDG) goal five calling for full gender equality. This struggle for gender equality and women's rights is not unique to Iran or the Middle East. Women's physical security is still extremely limited throughout much of the world. Despite international treaties being established to protect the rights of women and combat gender-based discrimination and violence, The Convention on the Elimination of All Forms of Discrimination Against Women (CEDAW) and other international conventions remain either unratified or sometimes unenforced by their signatories.

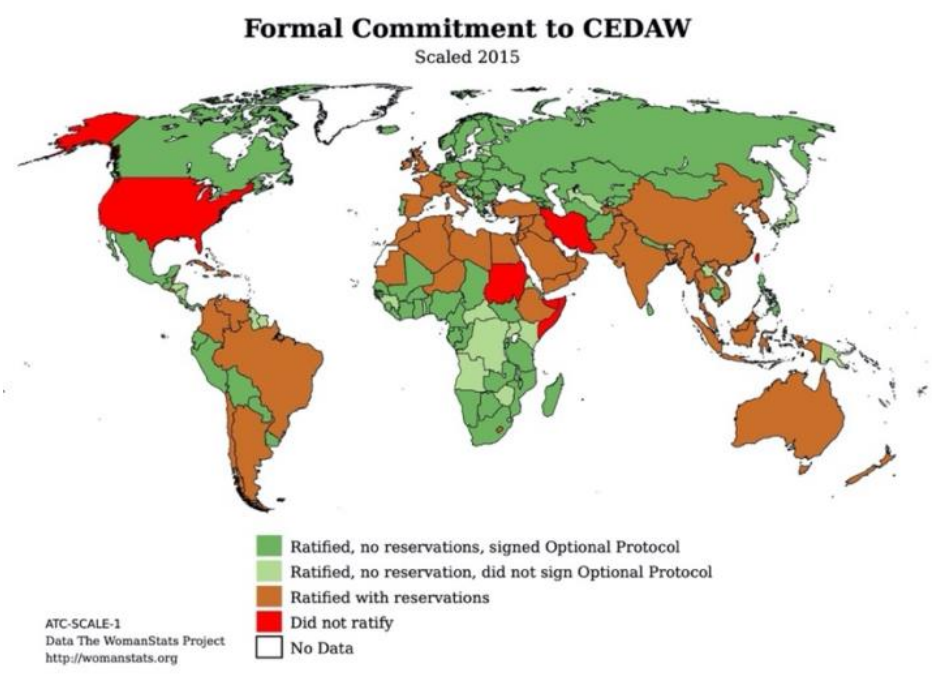

Figure 1 - Woman Stats - Formal Commitment to CEDAW

Neither the US nor the IRI have ratified the Convention to Eliminate Discrimination Against Women. 


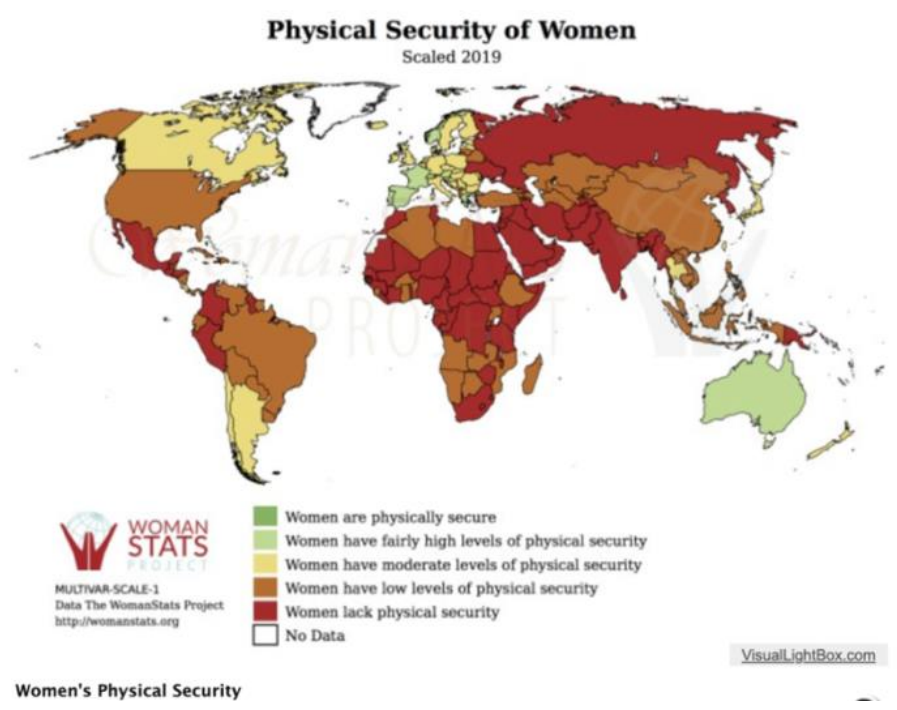

Figure 2 - Woman Stats - Women's Physical Security

In nearly all parts of the world women have low to moderate levels of physical security, or lack security entirely. This problem is not specific to any region, demonstrating that the need to create public spaces and environments where women feel safe is a global and pressing issue. An individual's ability to benefit from socio-economic mobility and opportunity often rests on their ability to access and participate in public spaces. The high level of insecurity and threats to their physical beings that women are forced to withstand in order to carry out their everyday activities prevents the larger aim of gender equality. In other words, it is only when women feel they are free from harm, or only equally as threated as their male counterparts, in public space that the foundation of a societal structure that supports and promotes gender equality can be constructed. 
The use of ICT by state and non-state actors has influenced the policies of both authoritarian and democratic governments, but the use of social media activism takes drastically different forms in these two contexts. This paper focuses on the use of collaborative processes by social movements in the case of Iran. An examination of the use of digital media and other technologies to promote human rights and social justice contributes to an interdisciplinary perspective in fields including but not limited to social movement theory, collective action, revolutions, information technology, and science and technology policy. By constructing collective identity and building solidarity online, social movements are able to both document repressive state behavior as well as challenge existing power dynamics, including issues such as police brutality, establishment violence, and gender discrimination.

Jeroen Van Laer and Peter Van Aelst's "Digitalized Action Repertoires” claims that social movements harness the power of digital media to promote their causes and accomplish their goals. The networked public sphere of the internet has allowed for innovative tactics with which social movements can construct collective identities based on shared grievances and opportunities. These digital media have also provided movements with a vital resource to achieve international visibility, publicity and attention. It is difficult today to find a social movement or collective cause that is not in some form supported by digital media or the internet. "Internet and Social Movement Repertoires: Opportunities and Limitations" uses two dimensions to analyze the interaction between online and offline activism: 1) the extent of internet use and 2) thresholds to participation. The second dimension includes cost-benefit, risks, and issues of identity at the movement or internal level while also being strongly influenced by the regime type and international environment. 


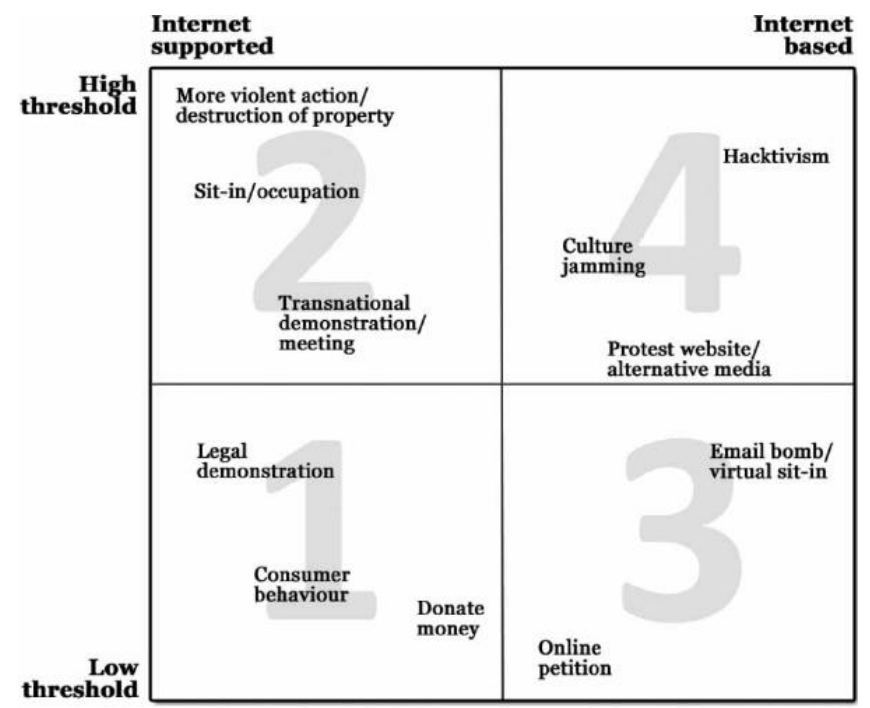

Figure 3 - Internet and Social Movement Action Repertoires (Jeroen Van Laer \& Peter Van Aelst)

Online spaces offer anonymity but mobilizing into physical public spheres by promoting a real-life protest via Facebook or other social media brings with it additional participant costs, especially in repressive contexts. Even online behavior has the potential to reveal an individual identity, potentially leading to negative consequences for online activism. For instance, companies and governments collect and track user activity to create targeted advertisements and customize user services. Platforms and technologies ask users to create accounts or online identities either immediately upon using the technology or as a prerequisite for access to particular features or services. It is argued that social movement scholars should see thresholds to participation as occurring on two levels or stages - online action and offline - each of which entail different costs.

Given the risks associated with engaging in resistance and protest in repressive contexts, why do these social movement actors still choose to engage in online activism? As is often the 
case under authoritarian contexts, individuals who refrain or are prevented from participating in formal policy instead organize in and around institutions that are not within the scope of traditional or conventional politics. Given this exclusion by the state, movements resort to engaging in unconventional political participation. For example, the Muslim Brotherhood is an influential group in Egypt, but the organization was banned from participating in Egyptian politics prior to the country's 2011 revolution. By creating an identity in opposition to the state, these movements succeed in putting pressure on repressive regimes to be more responsive to the needs of civil society. Thus, through effective and innovative uses of technology, social movements have successfully pushed for democratization and human rights that benefit marginalized and vulnerable segments of the population.

\section{ICT in the MENA Region and Iran}

Access to affordable and reliable internet contributes to socio-economic development (World Bank 2019).i Iran has a mixed record when it comes to investment and progress with ICT, but it is also one of the top countries designated as an enemy of the internet (Freedom House). Despite widespread, harsh censorship, Iranians are skilled at circumventing these restrictions through VPNs, filter breakers, or even transferring data through satellite TV signals.

\section{Democracy and Socio-economic Development}

Political scientists often refer to the forms and processes of the state by using terms such as authoritarian, totalitarian or democratic. Distinctions between these regime types are increasingly difficult to make because many of the world's current regimes exhibit at least some characteristics of an institutional electoral democracy. Countries such as Iran fall short of being classified as "liberal democracies". The state systematically denies its citizens basic civil and 
political rights such as the right to assembly or petition the government. Because of this repression, social movement actors in authoritarian governments often partake in more implicit, subtle forms of opposition.

The internet has allowed for the flourishing of subtle, subversive protest under repressive governments that are skilled at silencing the voices of dissent and opposition. ICT innovation impacts the way collective communities such as social movements form and behave. These innovations have also brought with them new policy concerns. Many of these concerns are related to internet or media regulation such as storage, privacy and online authentication. This paper argues that access to and protection of a free and universal or open global internet is in the best interests of actors at all levels of analysis. Access to affordable and reliable communication technology benefits mass public knowledge, information dissemination, collaboration and innovation. Any attempt to fragment or exclude populations from the international digital public sphere should be deemed as unjust, undemocratic and a threat to international security.

Despite what social media protest literature correctly points out as the privatization of the online public sphere, innovative use of the internet has allowed social movements to successfully campaign for global human rights and social justice issues. By using crowd and open source technologies, these groups combat crime and corruption occurring on a local or individual level by garnering transnational support. These movements successfully construct collective identities to promote values such as transparency, accountability, corporate responsibility and human dignity.

While dissident movements in authoritarian countries have emerged due to increased economic difficulties, this provides only a partial explanation for the rise of people power 
movements in the Middle East. To be clear, the Arab Uprisings and the Iranian Green movement had clear economic grievances. However social justice and democratic claims such as those promoting human rights, freedom of speech and ability to participate in a open, transparent democratic political system were primary goals of the movements. Armed with the internet, these collectives also had the resources necessary to mobilize to express their shared grievances and form collective identities. The use of technology to express a combination of economic and non-material demands can be seen through the Kefaya (Enough) movement's slogan of "Bread, butter and social justice" leading up to the 2011 Egyptian revolution.

The Importance of Context: Social Movement in a Climate of Fear

The use of media and communication information to facilitate state repression and establishment violence is an effort to minimize threats to state sovereignty and strengthen the regime's grip on power. While these threats to internet freedom and basic civil and political rights hinder democratization in countries like Iran, a multitude of international actors are outspoken proponents of preserving the internet as a space for open and free discussion and collaboration, actively fighting for and protecting internet freedom and maintaining a democratic virtual public sphere.

There are various approaches to studying social movements and social movement organizations (SMOs). Three dominant theories include that of relative deprivation, resource mobilization and new social movements (NSMs). Relative deprivation is when people compare achievements and realize they are not getting their fair share, thus they join social movements. Resource mobilization occurs when social movements have access to key resources such as knowledge, money, media, labor or solidarity. Unlike these two traditional social movement 
theories, NSMs emphasize the achievement of non-material goals. Instead of focusing on conventional forms of contention such as street protests, NSM theorists focus on sources of social movements such as politics, ideology, and culture. Because their products and goals are intangible goods, NSMs are not subject to the limitations of traditional collective action. Like the contributors to open source software (OSS), online social movement actors often innovate without the expectation of financial reward. Instead, these actors are motivated by non-financial social incentives such as improved reputation or respect for human rights.

\section{Social movements as technological innovators}

Technology has also reinvented productivity and collaboration in the world's capitalist marketplaces. Yochai Benkler (2011) argues that the internet has brought about two major changes: the expanded role of nonmarket enterprises and radical decentralization.ii Thomas Malone's (2015) collective intelligence similarly examines the shift to user or non-expert production of knowledge on the internet.iii By analyzing collective connection cases and the inclusion of non-experts, Malone addresses how to enable people and computers to connect in a way that will allow individuals to act more intelligently than any person, group, or computer. Projects such as NASA Mars Clickworker where over 80,000 people volunteer to successfully identify two million craters on Mars show how results collected from crowd-sourced, usercollective projects are just as accurate as results gathered from the work of highly qualified PhD students. These innovative uses of technology for collaborative projects demonstrate the potential of computers to challenge human intelligence and social capital.

Benkler argues, "the reorganization of production, and the advances it can bring in democracy, autonomy, and social justice will emerge, if it emerges, only as a result of social and 
political action." iv He also draws attention to the potential behind the internet's decentralization, leading to the emergence of nonmarket, nonproprietary production and distribution. This allows groups like Ushahidi, a technology non-profit with the aim of helping marginalized people raise their voices, and other non-governmental organizations (NGOs) to recruit volunteers from all over the globe in order to achieve its goals. The internet has brought with it the tremendous power of large-scale creative collaboration. The only question remains how these new developments will evolve under the repressive conditions of authoritarian governments.

The importance of motivated users or participants is critical to the study of social media activism. In other words, digital media technologies are only able to contribute to social movement success if the collective already has a strong user base. In an interview with MSNBC, on-the-scene journalist Richard Engle explains the overthrow of Mubarak in Egypt not as a Twitter revolution, but rather as the mobilization of long-standing offline identities through the use of digital media and social movements in the period immediately preceding the 2011 revolution. "This didn't have anything to do with Twitter and Facebook. This had to do with people's dignity, people's pride .... Now, the protests and the Twitter and all the social networking stuff helps ... but that's not why they're out. They're out because of mismanagement and a system that has really gotten so far away from its people." v. In short, it is not digital media or ICT, but the people behind these tools that allows them to be used for social movement success.

ICT Interventions and Democratization - Internet as Public Sphere

It would be difficult to identify a social justice or human rights advocacy group that does not have some form of online presence. Firms, governments, and a range of other actors use 
digital media to reach a larger audience and to make their information more easily accessible. While almost every organization today has a website and social media account, this does not necessarily mean that these online spaces are reaching an audience or promoting collaboration or democratic discourse. This raises important issues of trust, attention, and visibility of social movements operating online.

Melissa Loudon and Theo Mazumdar address the use of technology as both an enabler of protest mobilization for social movements as well as a tool for repression of dissent by the state. The authors conclude that the use of particular technologies seems to be more helpful in promoting protest. Testing the hypothesis that mobile devices were most influential in spreading information and mobilizing individuals, to take to the streets, the authors found that the use mobile phones was not as significant for protests as were social media platforms like Facebook and Twitter.vi

Attention and Trust: Using Technology to Examine Collective Behavior

Along with the flood of information available today, consumers of digital media are often overwhelmed by the sheer amount of content available. While this increased data has tremendous potential for researchers to analyze the actions and events occurring in the online public sphere, the average user is simply thrown into an ocean of information that can be difficult to navigate. This leaves content consumers highly susceptible to the dangers of misinformation and media bias. Even technologically savvy users are at risk of falling prey to fake news and information or cyber-attacks. In this struggle for attention, social movements can learn valuable lessons from successful online campaigns launched by brands on social media in order to increase their impact and engagement online. 
The rise of user generated content and commons-based peer production has brought with it a media revolution that challenges existing relations between the state and civil society. Previously, protest materials were kept underground and only disseminated decades later through outlets outside of the country. For example, Hengameh Golestan was one of the only photographers to document Tehran's street protests against compulsory hijab during the 1979 Islamic Revolution. Golestan quietly and carefully kept her negatives of the February 1979 events until she was safely able to develop and publish them as part of her 'Witness 1979' series.

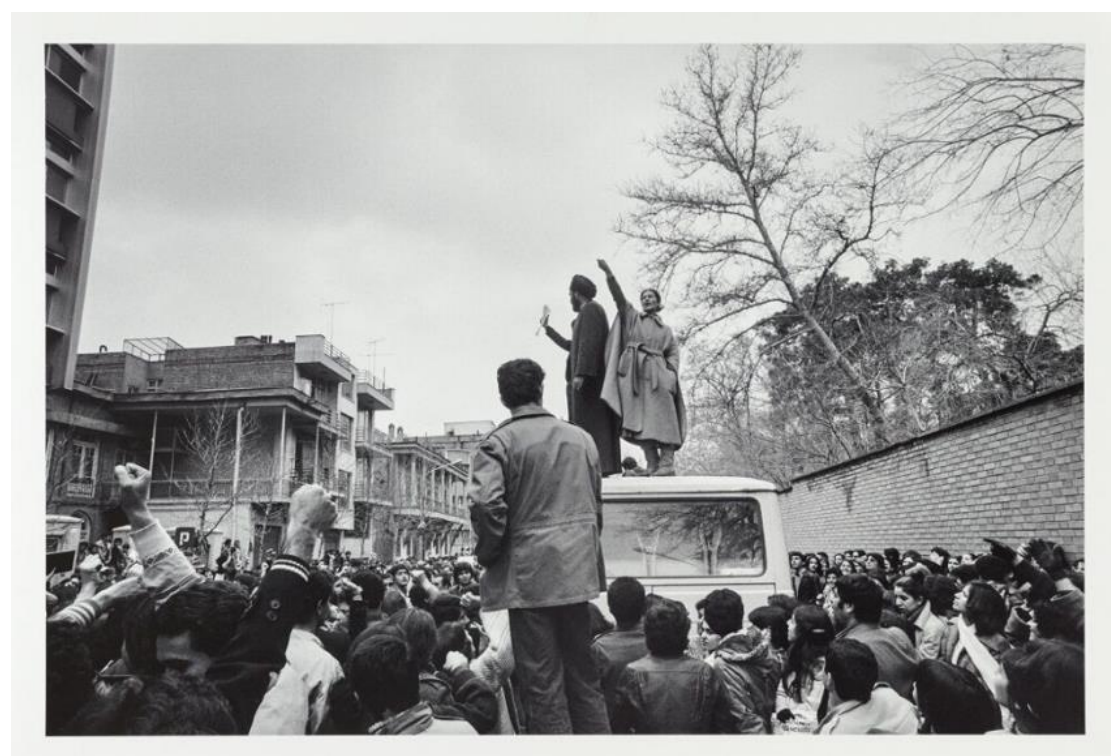

Figure 4 - Hegameh Golestan - Witness 1979 Seriesvii

With the development of technology, individuals are capable of becoming a journalist and human rights advocate as citizens of the world have stepped up to the challenge and successfully used their mobile phone cameras as weapons against injustice. Promoting universal human rights such as freedom of speech, internet freedom, and human dignity, these groups 
mobilize (often non-violently) both online and offline in order to protect and promote social justice. These groups are also able to overcome issues of trust by establishing reciprocity to establish and maintain strong cooperative relationships both on and offline.

\section{A Push for Techno-Ambivalence}

Much of the literature addressing the use of social media, or social networking, by social movements falls within one of two camps: the techno-optimists and the techno-pessimists. Kidd et. al. suggest a middle ground between these two extremes that takes into consideration both the limits and the possibilities of social movements using new technologies to organize and mobilize collective action. Drawing from the arguments and cases presented by both of these perspectives, this paper approaches the case of the Iranian women's movement from a position of technoambivalence.

\section{Techno-optimists}

These scholars overestimate the power of new technologies. Scholars promoting this perspective include Clay Shirky (2008) who argues use of social media to galvanize activism. Manuel Castells (2011) agrees with Shirky, positing that social media is critical, but there is also a need for real life interaction. Movements are often leaderless. Other scholars who examines the use of social media to effect change are Jennifer Aaker and Andy Smith (2010) and Phillip N. Howard (2015).

\section{Techno-pessimists}

In opposition to techno-optimists, techno-pessimists argue that social media technologies either have not (significantly) changed the way social movements form and evolve, or that these technological advances are actually hindering the ability to organize collectively for socio- 
political change. Techno-pessimist scholars include Malcolm Gladwell (2010), Evgeny Morozov (2011) and Navid Hassanpour (2014). Christian Christensen (2011) argues that media is just as useful for powerful leaders as they are for protestors, citing example of the repression of protesters using surveillance and monitoring in 2009 Iran.

Similar censorship and privacy breaches exist in other authoritarian countries such as China. The high level of Chinese regime technical literacy allows officials to constantly surveil the population through applications like WeChat which serve as a one stop shop for citizen transactions. Transportation, banking, groceries and other services are available through the app, allowing the state to track and monitor individual activity. The country's sophisticated registry and facial recognition also help construct a surveillance state. Domestic and foreign users who abuse WeChat or 'spread malicious rumors' such as commemorating or discussing Tiananmen Square, are blocked from the app.viii By 2020, China hopes to have a social credit system fully operational nationwide. Introduced in 2014 , the program has been piloted in several cities is also experimenting with using social ranking systems to reward favorable behavior and punish or publicly naming and shaming citizen transgressions.ix Surveillance and civil rights abuses are even harsher for China's predominately Muslim populations (Uighurs, Kazakhs, Uzbeks and Kyrgyz) who are forced to submit biometric information and are subsequently surveilled and punished by police for even the smallest offense. $x$

\section{A Third Path: Techno-ambivalence}

A preferred alternative to techno-optimists and techno-pessimists is techno-ambivalence as it considers the arguments and evidence of the techno-optimists and techno-pessimists. Techno-ambivalent scholars include Dhiraj Murthy (2013), Pablo Gerbaudo (2012) work on 
choreography of collective action, Sherif H. Kamel (2014) study of the 2011 protests in Egypt, and Anastasia Kavada (2015) analysis of ICT use during Occupy Wallstreet. Daniel Kreiss and Zeynep Tufecki (2013) argue that while the decentralized structure of the occupy movements was beneficial in some respects, the same structure made it difficult to achieve a coordinated response or decision. For example, when noise complaints were made because of the Occupy drum circles in New York, the Zuccotti protests were almost shut down because the protesters could not coordinate (despite having access to social media and new technologies).xi

Sreberny and Torfeh (2016) and Bajoghli (2019) write from a perspective of technoambivalence to specifically address the media environment in Iran. Bajoghli's Iran Reframed: Anxieties of Power in the Islamic Republic provides an in-depth account of pro-state media production within the country through extensive ethnographic work with members of the Islamic Revolutionary Guard Corp (IRGC). The book provides a nuanced view of media production in the IRI, challenging the misconceptions that authoritarian regimes practice ubiquitous censorship and repression.xii Cultural Revolution in Iran: Contemporary Popular Culture in the Islamic Republic focuses on the underground world of new technology, media and entertainment to demonstrate how despite the religious conservativism of the establishment, Iranians are able to use creative cultural practices to successfully negotiate and resist the repressive system.xiii Hashtags, Memes, Trolls: Communication and Collective Action in the $21_{\text {st }}$ Century

Hashtags were established relatively recently as an organizing mechanism on social media. Hashtags were first used on Internet Relay Chat (IRC) in 1988 to label groups and topics that were available across the entire network. This helped group similar messages and made it easier for users to find the information they were looking for. It was not until 2007 that using hashtags 
to organize groups and communities on Twitter was suggested by Chris Messina. In 2009, Twitter finally embraced the use of the hashtag and introduced a search tool so that users could see who else was using a particular hashtag. In 2010, Twitter introduced “Trending Topics," which displays the most popular hashtags on the platform at a given time.xiv

Eventually, hashtags became popular on internet forums and social networking platforms and were used to index topics and make them searchable, connecting all users who use the term or phrase. Hashtags are completely user generated, which means that anyone can create a hashtag by simply placing a \# symbol in front of a word or phrase, but the popularity of that hashtag can vary. Hashtags are a way for users to sum up their posts or self-select into groups or conversations. An individual might post something about their professionally productivity and end with \#workhard. Some hashtags have become consistently used by online communities through their temporal repetition or common knowledge, such as \#tbt (Throwback Thursdays), an internet trend where users post nostalgic pictures of their past accompanied by the hashtag \#tbt. Other hashtags have much shorter life spans and are only used surrounding a particular event or moment (ex. Superbowl, elections, etc.).

Hashtags are more popular on some platforms than others. Twitter and Instagram in particular, two of the most popular social media platforms used by Iranians, see the most widespread use of the hashtag. Hashtags are also used for Twitter Trends, which tracks trending topics on Twitter. Two recent trending topics on Iran - \#IranProtests and \#Soleimani demonstrate how despite the absence or tension of formal diplomatic relations, policy issues involving Iran are still prominent in online discussions. 
The history of the use of hashtags on internet platforms demonstrates the important role technology companies play in supporting or opposing features. If Twitter never agreed to indexing hashtags in 2009 , hashtag use may not be as prominent today. Other feature changes and updates from Twitter are also important to note for this project. Several features (Table 1) have been added to Twitter since its launch and are essential to consider when analyzing the use of the platform by social movements.

Table 1 - Twitter Added Features (2013-2017)

\begin{tabular}{|l|l|}
\hline Year & \\
\hline $\mathbf{2 0 1 2}$ & $\begin{array}{l}\text { Twitter mobile app made available in Farsi and Arabic, allowing users } \\
\text { in the region to use their own language to communicate.xv 1 }\end{array}$ \\
\hline $\mathbf{2 0 1 3}$ & Twitter launches a music app called Twitter Music for the iPhone. \\
\hline $\begin{array}{l}\text { April/ May } \\
\text { Nov 2015 }\end{array}$ & $\begin{array}{l}\text { Twitter introduces quote tweets (a form of retweet). } \\
\text { symbol (used to symbolize favoriting) with a heart symbol. }\end{array}$ \\
\hline May 2016 & $\begin{array}{l}\text { Twitter announces that photos, videos, and the person's handle will } \\
\text { not be counted in the 140 characters, and that a tweet beginning with a } \\
\text { handle will be seen by followers. }\end{array}$ \\
\hline Nov 2017 & $\begin{array}{l}\text { Twitter announces doubling the traditional 140-character limit to } \\
\text { 280 characters for all users. }\end{array}$ \\
\hline
\end{tabular}

\section{From Memes to Movements}

A meme is a photo, video or short text that spreads rapidly from person to person through non-genetic means, especially through imitation. The term was introduced in 1976 by British evolutionary biologist Richard Dawkins in his work The Selfish Gene. Like the spread and mutation of genes in biological evolution, internet memes evolve, change and often go "viral" or gain tremendous popularity on social media platforms and the internet at large. Like hashtags,

1 Previously, tweeting in Arabic or Farsi meant using Latin characters to spell out what the Arabic or Farsi word might sound like. In addition to this being an imprecise solution, it also led to various alternative spellings for the same word or phonetic/translation of a letter (ex. Farsi $\varsigma$ could be seen as a Latin I, ee, ey, or y). 
memes are completely user generated and because of their simple and often silly nature, they encourage widespread participation, making them the perfect tool for social movements seeking to mobilize members.

The creative and expressive nature of these cultural objects make them particularly effective in repressive or authoritarian contexts as they allow activists to express their views while avoiding detection and repression by the state. These memes and digital campaigns also hold personal and collective significance. While most memes are created within the general guidelines or structure of those that came before it (what makes it a meme), there is also room for individualization and personalization. Users reproduce the meme with their own individual flare, or in the case of MSF and related campaigns, with their own faces or bodies performing the call to action, whether documenting themselves walking unveiled in the street or attending a soccer match disguised as a man.

\section{Successful Digital Campaigns - \#metoo and \#blacklivesmatter}

The power of memes and hashtags lies in their ability to create shortcuts for societies and other groups to discuss complex or controversial issues. For example, online activists use the hashtags \#metoo and \#blacklivesmatter to raise awareness about and discuss controversial topics like sexual assault and police brutality, issues that were rarely explicitly addressed in public or spoken about openly. In the same sense, everyday objects can be repurposed and used as symbols of subtle resistance. Examples include the use of yellow umbrellas in 2014 Hong Kong, wearing sunglasses in a profile picture in China, or the use of green or white headscarves, ribbon or clothing in Iran. Social movement practices often evolve with new developments and innovations in technology. As the author of Memes to Movements explains, the popular practice 
of a user changing their avatar or profile picture to show his or her beliefs has become the equivalent of activists wearing an armband or t-shirt in previous decades. By posting a profile picture with a rainbow, one shows symbolic solidarity with and support for LGBTQ rights without having to explicitly type or state this view or belief. The impact this has on people's social media feeds is significant. When a user scrolls through his or her feed, they see each user's profile picture next to their post, making it easy to gauge how many users in their network support a particular cause.

\section{Power of Images Online}

Much of these online movement tactics (memes, hashtags, etc.) have one thing in common: they use the aesthetic appeal of visual (especially human) content to cut through the flood of information on social media platforms and gain attention.

Images help social movement attention and mobilization, mitigating the opportunity costs associated with activism, potentially creating a positive cycle of online resistance and protest. By showing their faces and taking selfies, members of the IWM and other Iranian social movements practice Bayat's power in numbers, lowering the costs of participation noted by Van Laer and Van Aelst. For example, MSF activists are less afraid to post videos or photos of themselves in public without hijab because if hundreds of thousands of Iranian women are removing their hijabs, they are less likely to be arrested or intimidated by morality police. This shift from more stealthy or subtle protest can be seen when women went from mostly videotaping themselves or having their colleagues video record them from behind walking without hijab without showing their faces to posting photos and videos showing the face of the user and sometimes even stating names and personal information. This shift in posting anonymously or without identifying 
information to posting with real names and faces shows the power of the internet to mitigate risks of activism and bring people to action despite the potential negative consequences of mobilizing under an authoritarian government.

Images also provide several other benefits for social movement activists organizing and mobilizing online. Pictures and images cut across or help overcome language barriers - even those without Farsi language skills are able to understand the overall message of the movement. Even if the context or content of the media is unclear, users will often engage in conversation to help community members who speak other languages explain and understand what is happening. Socio-psychologically, human beings are attracted to images, and in particular images containing people or human beings. Eye tracking studies demonstrate that despite individual differences in viewing behavior, viewers are attracted to certain similar areas within pictures, such as people. Other studies demonstrate the importance of people on company website images as they make the organization seem more personal and attractive. When looking at a webpage, users reported more positive feedback about a website if it displayed an image containing people.

\section{Data, Methods and Findings}

\section{Data Collection}

Twitter Harvesting

Twitter data was harvested on MSF and related hashtags including White Wednesdays (WW), My Camera is My Weapon (MCW) and Blue Girl in both English and Farsi language. Tweets were collected in real time from 2018-2019 through various tools (Social Feed Manager, Python) and using the researcher's Twitter credentials to access Twitter's Application Programming Interface (API). Tweets were collected at three levels: specific movement hashtags, general topic terms, and all Persian language tweets. 


\section{Semi-Structured Interviews and Other Sources}

Semi-structured interviews with movement members including translators and content moderators supplemented the Twitter data collected and analyzed for this project. Other social media platforms, such as Instagram, Facebook, WhatsApp and Telegram were also monitored. Much of the content for the MSF and related campaigns were cross posted on these various platforms. Because of this frequent cross-posting and content replication, the analysis of Twitter provides a relatively accurate picture of the online discourse related to the movement across platforms.

\section{Semi-Structured Interview Findings}

The MSF campaign is run by a small group of volunteers and associates of Masih Alinejad. Most of the movement members work remotely from international locations (Iran, Europe, Canada, United States, etc.), translating movement content and guiding Masih's public relations campaign. There are various accounts that are loosely affiliated with the movement. One of the campaign's lead volunteers mentioned that given the open and public nature of the digital campaign, the movement does not get to choose who it interacts or is associated with. Some volunteers interviewed mentioned that they believe the IRI is involved in a campaign against the movement, seeking to disrupt their efforts to mobilize and gain attention and support for their cause. Attacks against the campaign range from minor harassment to threats and privacy breaches. Interviews with movement activists revealed several stories of the regime attacking protestors online, especially those that are vocal about their opposition to the current regime. Three levels of data 
To analyze the online public discourse surrounding the My Stealthy Freedom and related campaigns, three levels of data were collected and analyzed.

\section{Persian Language Twitter Methodology}

In order to provide an overview of what is being discussed in Persian on Twitter, all Persian tweets were collected. The method of collecting all Persian tweets consisted of running a query for a list of Persian stop words and the Persian alphabet. The search for all tweets using Persian language was established in September 2019. Analysis of social movement activity and critical events through this unique data allows for empirical evidence of patterns and trends during moments of local, national and international importance.

\section{Topic level key terms and movement hashtags}

To provide a meso-level analysis of the public discourse surrounding women in public space, terms such as woman/women and hijab were collected and analyzed. Many of these terms overlapped with results of the specific movement hashtags such as women and hijab. The third and most detailed level of analysis involves campaign specific hashtags such as My Stealthy Freedom, White Wednesdays and My Camera is My Weapon. Additional IWM terms such as Blue Girl and terms related to Nasrin Sotoudeh (\#freeNasrin) were also collected and analyzed in order to examine the discourse surrounding these particular individuals and events related to women in public space in the IRI.

\section{Variables, Research Questions and Hypotheses}

After tweets are collected, several variables are created to analyze the use of the social media platform by the IWM. These variables include retweets/favorites count (DVs), character count, 
hashtags, media, readability score, user friends count, user followers count, account age, reply count, and quote count (IVs) (Table 3 - Variable Descriptions).

\section{Hypotheses}

In order to measure the impact of the use of media, hashtags and content on audience attention, the following hypotheses are tested:

H1: The use of images will significantly increase retweet (and favorite) count.

H2: The use of hashtags will significantly increase retweet (and favorite) count.

H3: Social network analysis (SNA) of movement co-occurring hashtag graphs will reveal information about network structure and interactions.

Data analysis

Table 2 - September 2019 Top Persian Hashtags

\begin{tabular}{|c|c|c|}
\hline Farsi/Persian & English Translation/Topic & Count \\
\hline حب_الحسين_يجمعنا & The Love of Hussain Unites Us & 219350 \\
\hline $\mathrm{EXO}$ & K Pop & 122917 \\
\hline BloodLustRegimeMustGo & BloodLustRegimeMustGo & 89186 \\
\hline الأربعين_مقدمة_الظهور & $\begin{array}{l}\text { Arbaeen is the introduction to } \\
\text { the return }\end{array}$ & 79184 \\
\hline الحسين_يجمعنا & Hussein unites us & 67610 \\
\hline إيران & Iran & 61731 \\
\hline دفاع_مقس & Holy Defense & 53767 \\
\hline ل لردخان & Lordegan & 50985 \\
\hline هِيكو & Hepco & 47197 \\
\hline شهيد & martyr & 44641 \\
\hline
\end{tabular}

Total Tweets: $15,175,875$

The top words and phrases used in Persian language Twitter from Table 2 focus on religious and militarist topics. Discussion about the prophet Hossein, the Arbaeen pilgrimage and martyr are frequent. Other topics include instances of collective action and protest. For example, 
the Lordegan hashtag was used by users from the town Lordegan to disseminate accusations that 300 people in the community were infected with HIV during a diabetes screening.xvi The HEPCO hashtag was used during labor protests that arose due to increased layoffs and increased mismanagement at the Heavy Equipment Production Company (HEPCO) after the industrial complex was privatized in 2017. While HEPCO once employed over 8,000 workers, now only about 1,000 employees are left.xvii Security forces responded to both of these protests which were fueled by over 40,000 tweets each (over a two week period) with harsh repression, which these movements then captured via video and pictures and posted online to document these instances of establishment violence against non-violent activism.

A key finding of Persian language tweets is that there was a significant decrease in the number of Persian tweets during the internet blackout in November 2019 (number went from approximately one million/day to roughly $200,000-300,000 /$ day). This data suggests that a substantial proportion of the tweets being produced and collected in Persian language (approximately 75\%) are coming from inside Iran. 


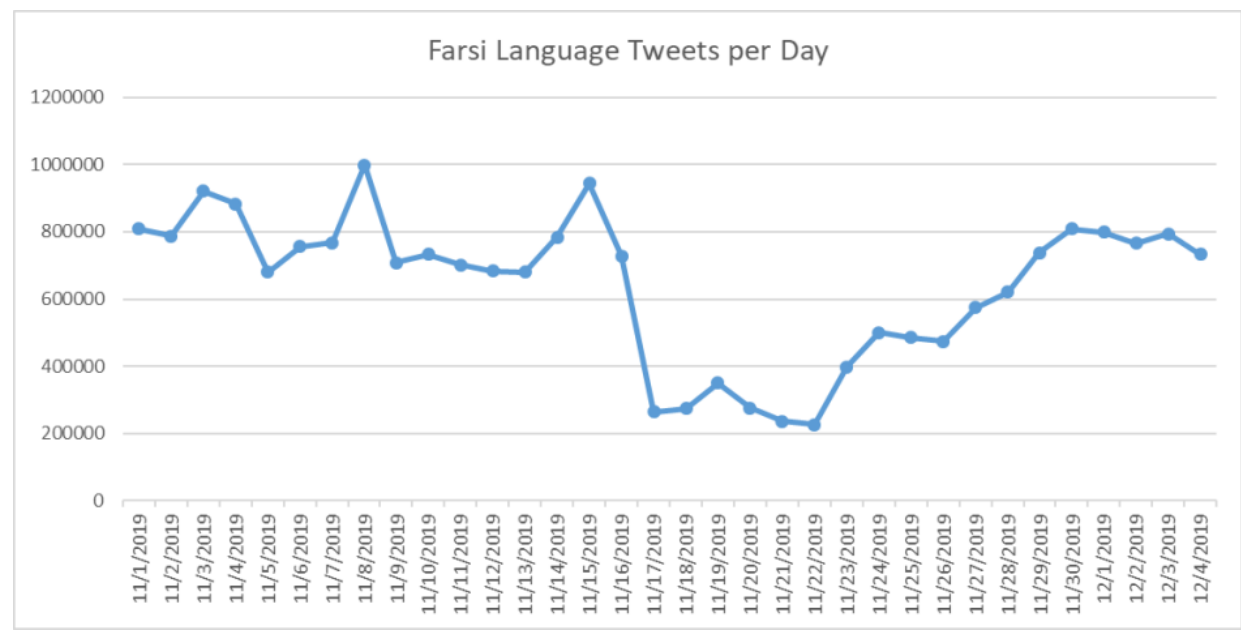

Figure 5 - Number of Farsi Language Tweets Per Day (November 2019)

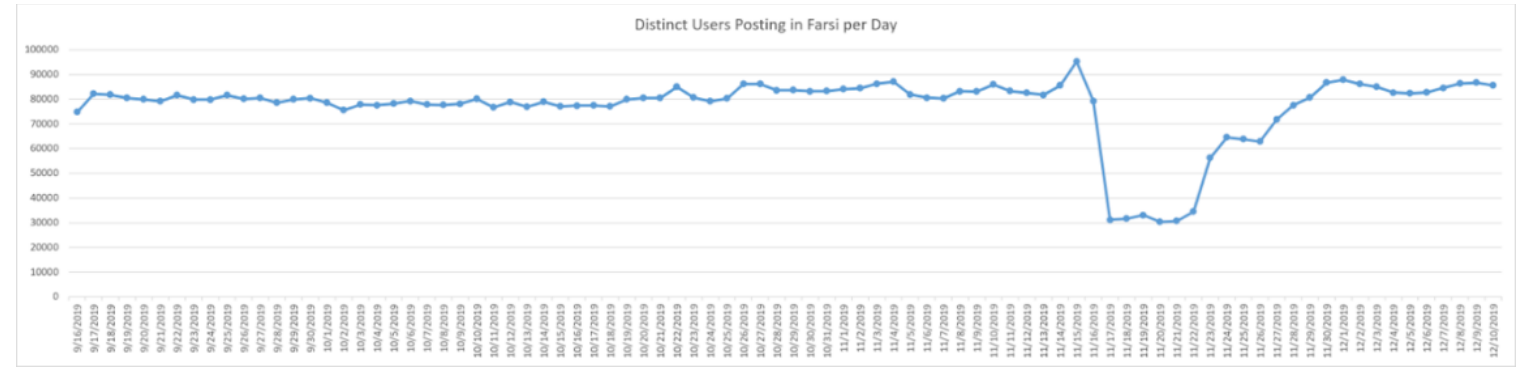

Figure 6- Number of Distinct Users Posting in Farsi Per Day (2019)

As seen in Figures 5 and 6, the number of Persian language tweets dropped comparably to the internet shutdown and the number of distinct users returned to relatively the same level once Iran came back online. Based on this data, it is reasonable to assume that many of the tweets collected both before and after the shutdown are coming from Iranians inside Iran (using circumvention software to access Twitter), supporting claims of the high level of Iranian technical skill.

MSF 2018 Methodology and Models 
The following data analyzes various tweet variables such as media count (images, video, hyperlinks), character count and hashtag count to determine how these factors influence the number of retweets a tweet receives. In this sense, retweets serve as a proxy measurement for impact, attention or influence on the microblogging platform.

Initial models measuring retweets included variables such as flesch reading ease score and sentiment analysis (Appendix - Initial Models). Model 1 contains only flesch reading ease score and media count as independent variables, with neither of these variables having a statistically significant impact on retweets (DV). Models 2 and 3 demonstrate that variables such as media inclusion in a tweet increases the number of retweets by 4 . As expected, other variables associated with influence on social media such as friends count and favorites count (how many times a user likes or favorites a tweet) also have a statistically significant positive impact on retweet count. After running these initial models, it was determined that favorites count should serve as its own dependent variable and that reading ease and sentiment should no longer be included as independent variables given that they did not provide any additional information or have significant impact on audience attention.

All tweets containing the movement phrases My Stealthy Freedom (MSF), White Wednesdays (WW) and My Camera Is My Weapon (MCW) were collected in both English and Farsi language. The tables below show the variable descriptions, descriptive statistics and regression results for the three movements with retweet count as the dependent variable. Independent variables include character count, hashtag count, media count, user friends count, user's followers count, favorite count and user account age (in days). These independent variables represent all factors that might impact a tweet's retweet count. 


\section{Table 3 - Variable Descriptions}

\begin{tabular}{|c|c|c|}
\hline Attribute & Type & Description \\
\hline Retweet Count & Integer & Number of times tweet has been retweeted. \\
\hline $\begin{array}{l}\text { Character } \\
\text { count }\end{array}$ & Integer & Number of characters in tweet. \\
\hline Hashtag count & Integer & $\begin{array}{l}\text { Number of words or phrases preceded by a hash sign (\#) used in tweet } \\
\text { to identify messages on a specific topic. }\end{array}$ \\
\hline Media Count & Integer & Number of media (images or video) in tweet. \\
\hline User Friends & Integer & Number of users account is following (AKA their "followings"). \\
\hline Count & & $\begin{array}{l}\text { Under certain conditions of duress, this field will temporarily indicate } \\
\text { " } 0 \text { ". The number of accounts that user follows that also follows them } \\
\text { (reciprocal). }\end{array}$ \\
\hline User's & Integer & Number of followers account currently has. Under certain conditions \\
\hline Followers & & of duress, this field will temporarily indicate " 0 ". The number of users \\
\hline Count & & following the account but is not followed back (non-reciprocal). \\
\hline Statuses Count & & Number of tweets by user. \\
\hline Favorite Count & Integer & Number of times tweet has been liked by Twitter users. \\
\hline $\begin{array}{l}\text { User Account } \\
\text { Age }\end{array}$ & Integer & Days since account has been created. \\
\hline Quote Count & Integer & $\begin{array}{l}\text { Number of times tweet was retweeted with comment. This allows for } \\
\text { the content of the original tweet to display on retweeting user's } \\
\text { timeline. }\end{array}$ \\
\hline Reply Count & Integer & $\begin{array}{l}\text { Number of replies to tweet. Comment shows below the original tweet } \\
\text { and not on the replier's timeline. }\end{array}$ \\
\hline $\begin{array}{l}\text { Mentions Top } \\
\text { User }\end{array}$ & Integer & $\begin{array}{l}\text { Number of times tweet mentions (@) a top contributor within the } \\
\text { dataset. }\end{array}$ \\
\hline
\end{tabular}

Variables related to tweets fall into two categories: 1) features related to the tweet 2) features related to the user. For example, User Friends Count, User's Followers Count and User Account Age all relate to the individual Twitter user, while variables such as retweet, media, hashtag, character count, and favorite count all relate directly back to the tweet.

It is important to understand how these variables impact influence factors such as likes favorites and retweets. For example, related to user data - a user with more friends or followers is likely to gain more attention and has a higher probability of receiving more retweets or likes because the account's content is seen by a larger audience. 
Various modes of engagement with a tweet can also help determine the individual tweet's popularity and the nature of discourse surrounding the issue. For instance, there are various ways a user might react to or share content from another user. These include retweets, favorites, quotes and replies.

\section{Categories of Tweet Engagement}

- Retweet - Sometimes called a "blind retweet," a retweet is when a user simply re-posts or shares a tweet without adding any additional content. Shares of this type can be equated to a blind support of a topic or comment, as the user is allowing this to be shared on his/her own timeline, making it visible to all people who follow that account.

- Favorite - Liking or favoriting a tweet involves clicking on the heart icon under the tweet content. This is similar to retweeting in that it is essentially endorsing the tweet's content, but the original message does not appear in the timeline of the person who liked or favorited the tweet.

- Quote - Similar to a retweet, a quote tweet is one where the user also retweets the original content but chooses the option to "Retweet with Comment". When using this option, a user retweets the original tweet and adds their own post above. For instance, users could add additional hashtags, mention other users who might be interested in viewing the content, or they could post a comment supporting or opposing the original tweet. In this sense, a quote tweet still replicates the original tweet content, but the comment that is added could be positive, negative or neutral.

- $\quad$ Reply - Replies are responses to a tweet. Unlike retweets and quotes, a reply tweet does not cause the original tweet to display on the timeline of the user engaging with the tweet, 
and thus could be positive or negative. In other words, reply count depicts the level of engagement with a tweet but tells the researcher little about if this engagement was either positive or negative.

Table 4 - MSF 2018 Descriptive Statistics

$\begin{array}{lllll}\text { Attribute } & \text { Mean } & \text { SD } & \text { Min } & \text { Max } \\ \text { Retweet Count } & 28 & 292.7717 & 0 & 10228 \\ \text { Character count } & 123 & 26.18365 & 18 & 152 \\ \text { Hashtag count } & 4 & 4.044617 & 0 & 19 \\ \text { Media Count } & 0.4 & 0.6959265 & 0 & 4 \\ \text { User Friends Count } & 2298 & 3779.532 & 0 & 38100 \\ \text { User's Followers Count } & 31563.78 & 638331.5 & 0 & 23915156 \\ \text { Statuses Count } & 31900.17 & 51679.99 & 0 & 711949 \\ \text { Favorite Count } & 53.54334 & 582.4339 & 0 & 20645 \\ \text { User Account Age } & 1862.644 & 1164.562 & 0 & 4233 \\ \text { Quote Count } & 4.393939 & 108.9117 & 0 & 4085 \\ \text { Reply Count } & 3.332629 & 52.45469 & 0 & 1932 \\ \text { Mentions Top User } & 0.06694856 & 0.250021 & 0 & 1\end{array}$

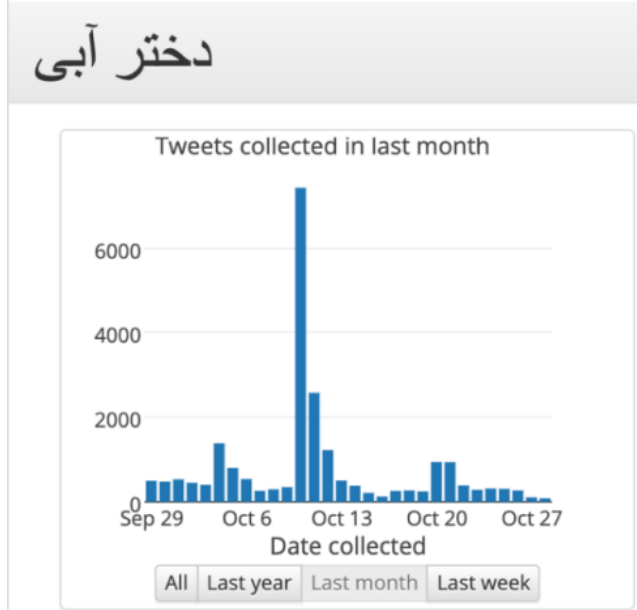

Figure 7 - 2019 Blue Girl Hashtag Use Over Time 
Data surrounding the Blue Girl case yielded two important findings. First, unlike the other women's movement campaigns such as MSF, Blue Girl appeared to be much more popular in Persian language than in English. Second, the hashtag witnessed a sharp spike on the day of the Iran-Cambodia match (over 7,400 instances on October 10th) with tweets related to the sale of stadium tickets to Iranian women for the first time in nearly 40 years. This peak use of the hashtag demonstrates how these phrases are widely used to serve a specific purpose and then quickly lose popularity after the key event has occurred. In this case, the phrase BlueGirl was used widely through mid-October and quickly declined in use after the match occurred.

$\begin{array}{lc}\text { @womensmarch } & 66 \\ \text { @justsimon13 } & 66 \\ \text { @yasmohammedxx } & 61 \\ \text { @miss9afi } & 60 \\ \text { @gadsaad } & 56 \\ \text { @faithlesshijabi } & 56 \\ \text { @imamofpeace } & 56 \\ \text { @mimzyv } & 56 \\ \text { @zarakay } & 51 \\ \text { @zarakayk } & 12\end{array}$

Figure 8 - MSF Most Influential Users

Surprisingly, the movement's founder, Masih Alinejad (@ AlinejadMasih) is not one of the movement's most influential users. However, figures such as Yasmin Mohammed 
(@yasmohammedxx) widely circulate content produced by Alinejad and her team of MSF volunteers.

\begin{tabular}{ll} 
\#mystealthyfreedom & 93 \\
\hline \#whitewednesdays & 90 \\
\hline \#mycameraismyweapon & 73 \\
\hline \#forcedhijab & 73 \\
\hline \#freefromhijab & 72 \\
\hline \#nohijabday & 65 \\
\hline \#awesomewithoutallah & 59 \\
\hline \#iran & 5 \\
\hline \#sisterhood & 3 \\
\hline \#freeiran & 2
\end{tabular}

Figure 9 - Top Hashtags

Figure 9 confirms that the top three phrases used by the IWM are the three campaigns that comprise the core of this study's analysis. Iran is also one of the top hashtags used in the campaign, demonstrating the movement's geographic focus. As will be seen later with the social network analysis (SNA), these campaigns also share co-occurring hashtags with women's and human rights movements in other regions of the world, establishing transnational connection and showing support and solidarity through online cultural production.

Top Users - Incorporating SNA into Regression Models

Examination of the top users associated with each campaign allows for incorporation of network relationships into statistical models. The top active user and top retweeted user mentioned variables were created to determine if mentioning one of the top ten most active users 
would increase retweet and favorite count. While digital or hashtag campaigns are often leaderless or decentralized, adding the top user mention variable allows us to determine if relating content back to a top contributing user increases the likelihood of engagement via retweet or favorites.

\section{Methodology for determining top user}

Adding top user first involves determining the top users within each campaign dataset.

This is done by finding the top contributing user for each set. The second stage involved looking through each tweet in the set and determining if it mentioned one of the top 10 contributing users. The variable 'Mentions Top User' ranges from 0 -10 with 0 being no top contributing users mentioned in the tweet and 10 being all 10 top contributors being mentioned.

Table 5 - 2018 Retweet Count (Top User Mentions)

$\begin{array}{llll} & \text { MSF } & \text { WW } & \text { MCW } \\ \text { Character Count } & 0.03 & 0.07^{* *} & 0.03 \\ & (0.05) & (0.03) & (0.06) \\ \text { Hashtag Count } & -0.75^{*} & -0.82^{* *} & 0.37 \\ & (0.35) & (0.31) & (0.79) \\ \text { Media Count } & 7.61^{* * *} & 5.87^{* * *} & -4.82 \\ & (1.92) & (1.20) & (4.36) \\ \text { User Friends Count } & 0.00^{* * *} & 0.00^{* * *} & 0.01^{* * *} \\ & (0.00) & (0.00) & (0.00) \\ \text { Users Followers } & -0.00^{* *} & 0.00 & 0.00 \\ \text { Count } & (0.00) & (0.00) & (0.00) \\ \text { Statuses Count } & -0.00^{* * *} & -0.00^{* * *} & -0.00 \\ & (0.00) & (0.00) & (0.00) \\ \text { User Account Age } & 0.00 & 0.00 * * & 0.00 \\ & (0.00) & (0.00) & (0.00) \\ \text { Quote Count } & -2.14^{* * *} & 13.02^{* * *} & 11.36^{* * *} \\ & (0.08) & (0.22) & (0.22) \\ \text { Reply Count } & 9.85^{* * *} & -0.63^{* * *} & 0.02 \\ & (0.18) & (0.17) & (0.18) \\ \text { Mentions Top User } & -5.05 & -7.48 & -11.54 \\ & (5.26) & (4.11) & (12.41) \\ \text { R2 } & 0.97 & 0.75 & 0.94 \\ \text { Adj. R2 } & 0.97 & 0.75 & 0.94 \\ \text { Num. obs. } & 1419 & 4869 & 1149 \\ \text { RMSE } & 48.23 & 51.98 & 65.19 \\ & & & \\ & & & \\ & & & \end{array}$


Top User Mentions (Table 5) shows that media count increases likelihood of retweet whereas increased hashtag count has a negative and statistically significant relationship with retweets. Quote and Reply count seem to have a relatively positive impact on retweet count with the exception of Quote Count for MSF (-2.14***) and Reply Count for WW $\left(-063^{* * *}\right)$ which are both slightly negative. This shows that each quote count or reply increases the likelihood of retweet, which makes sense. Quotes are essentially retweets with a comment that are then displayed on the posting user's timeline, thus giving the tweet exposure to a larger audience and increasing the probability that it will be retweeted. As has been seen in previous models, user variables such as Friends, Followers and Statuses Count all have statistically significant but minimal impact (coefficient $<0.001$ ) on retweet count.

Table 6 - 2017-2018 Farsi Retweets Count (Top User Mentions)

$\begin{array}{llll} & \text { MSF } & \text { WW } & \text { MCW } \\ \text { Character Count } & 0.01 & 0.09 * * * & 0.08^{* *} \\ \text { Hashtag Count } & (0.02) & (0.01) & (0.03) \\ & 0.05 & -0.52 * * * & -0.62 * * * \\ \text { Media Count } & (0.22) & (0.11) & (0.17) \\ & 0.67 & 5.60 * * * & 6.01 * * * \\ \text { User Friends Count } & (0.97) & (0.63) & (1.19) \\ & 0.00 & 0.00 & -0.00 \\ \text { Users Followers } & (0.00) & (0.00) & (0.00) \\ \text { Count } & -0.00^{*} & 0.00 * * & 0.00 * * * \\ \text { Statuses Count } & (0.00) & (0.00) & (0.00) \\ & 0.00 & -0.00 * * * & 0.00 \\ \text { User Account Age } & (0.00) & (0.00) & (0.00) \\ & -0.00 & -0.00 * * * & -0.00 \\ \text { Quote Count } & (0.00) & (0.00) & (0.00) \\ & 6.35 * * * & 3.73 * * * & 2.04 * * * \\ \text { Reply Count } & (0.56) & (0.06) & (0.07) \\ & 1.67 * * * & -0.52 * * * & 1.49 * * * \\ \text { Mentions Top User } & (0.14) & (0.03) & (0.04) \\ & -6.62 & -5.05 & -8.36 \\ \text { R2 } & (13.47) & (5.26) & (6.33) \\ \text { Adj. R2 } & 0.75 & 0.53 & 0.75 \\ & 0.75 & 0.53 & 0.75\end{array}$




$\begin{array}{llll}\text { Num. obs. } & 705 & 8399 & 3633 \\ \text { RMSE } & 13.42 & 31.56 & 37.21\end{array}$

Table 6 depicts a retweet regression using 2017-2018 Farsi language data. The results are similar to those of the English language regressions, though the impact of hashtags and media are is slightly less in Farsi than they are in English. For example, each additional media increase retweets by 5.60 for WW in Farsi but by 5.87 in English (at the $99 \%$ confidence level). The total number of tweets containing White Wednesdays are significantly higher than the number of tweets for the other two hashtags, showing that WW was the more popular hashtag campaign in both languages.

Based on the data in Table 7, 2019 Retweets and Favorites, hashtag count only increased retweets for MSF and WW. There was a negative impact of including additional hashtags on both retweet and favorite count for MCW. Media count is highly statistically significant for retweet and favorite count across all campaigns except for MSF favorites. Increase in use of media significantly increased favorite counts for WW and MCW and retweet count for MSF (2794.54). Surprisingly, inclusion of additional media led to a statistically significant decrease in retweet count for WW (-756.69) and MCW (-251.59). One limit to this model is its low level of explanatory value. Compared to the 2018 models which all had $\mathrm{R}_{2}$ above 0.75 , the $\mathrm{R}$ and $\mathrm{R}_{2}$ in Table 7 ranges from as low as 0.02 to 0.32 . 
Table 7 - 2019 Retweets and Favorites - Top User Mentions

\begin{tabular}{lllllll} 
& \multicolumn{2}{c}{ MSF } & \multicolumn{2}{c}{ MCW } \\
Character & Retweet & Favorite & Retweet & Favorite & Retweet & Favorite \\
Count & $-1.66 * *$ & $0.10 * * *$ & $-3.48 * * *$ & $0.40 * * *$ & -0.28 & $0.84 * * *$ \\
Hashtag Count & $(0.64)$ & $(0.01)$ & $(0.19)$ & $(0.01)$ & $(0.33)$ & $(0.01)$ \\
& $24.97 *$ & -0.15 & $133.56 * * *$ & $-1.31 * * *$ & $-70.77 * * *$ & $-5.25 * *$ \\
Media Count & $(12.35)$ & $(0.22)$ & $(3.56)$ & $(0.12)$ & $(4.87)$ & $(0.21)$ \\
& $2794.54 * * *$ & 1.21 & $-756.69 * * *$ & $56.91 * * *$ & $-251.59 * * *$ & $107.77 * * *$ \\
User Friends & $(47.56)$ & $(0.86)$ & $(29.15)$ & $(0.99)$ & $(46.89)$ & $(2.07)$ \\
Count & -0.00 & $-0.00 * * *$ & $0.01 * * *$ & $-0.00 *$ & $0.00 * *$ & $-0.00 * * *$ \\
Users Followers & $(0.00)$ & $(0.00)$ & $(0.00)$ & $(0.00)$ & $(0.00)$ & $(0.00)$ \\
Count & -0.00 & $0.00 * * *$ & -0.00 & $0.00 * * *$ & -0.00 & $0.00 * * *$ \\
Statuses Count & $(0.00)$ & $(0.00)$ & $(0.00)$ & $(0.00)$ & $(0.00)$ & 0.00 \\
& $0.00 * * *$ & -0.00 & $-0.00 * * *$ & $-0.00 * *$ & $-0.00 * * *$ & $-0.00 *$ \\
User Account & $(0.00)$ & $(0.00)$ & $(0.00)$ & $(0.00)$ & $(0.00)$ & $(0.00)$ \\
Age & $-0.09 * * *$ & -0.00 & $0.06 * * *$ & $-0.00 * * *$ & $0.05 * * *$ & -0.00 \\
Mentions Top & $(0.02)$ & $(0.00)$ & $(0.00)$ & $(0.00)$ & $(0.00)$ & $(0.00)$ \\
User & $1389.75 * * *$ & -0.95 & $419.90 * * *$ & $-2.28 * * *$ & $816.57 * * *$ & $-7.17 * * *$ \\
R2 & $(39.67)$ & $(0.72)$ & $(8.05)$ & $(0.27)$ & $(15.75)$ & 0.69 \\
Adj. R2 & 0.32 & 0.02 & 0.02 & 0.04 & 0.06 & 0.15 \\
Num. obs. & 0.32 & 0.02 & 0.02 & 0.04 & 0.06 & 0.15 \\
RMSE & 12843 & 12843 & 209814 & 209814 & 59629 & 59629
\end{tabular}

${ }_{* * *} \mathrm{p}<0.001,{ }^{* * \mathrm{p}}<0.01, * \mathrm{p}<0.05$ 


\section{Social Network Analysis}

In order to analyze the network structure of users and content of MSF and related campaigns, tweet data was processed to make maps in various social network analysis (SNA) software, including Netlyic, Socioviz, NodeXL and Gephi. While findings from retweet and friends network graphs were insightful, they mostly confirmed information such as the top active or most influential users in the network which were previously discovered during content analysis and interviews with movement members. More useful for this project's purposes was to construct co-occurring hashtags graphs that explain the relationship between hashtags related to the movement.

\section{Co-Occurring Hashtag Network Analysis}

In retweet network graphs the nodes are users and these nodes are linked through one user retweeting or friending another user. In co-occurring hashtag graphs the nodes are hashtags and the link between them is that they are used at the same time, or co-occurring, within a tweet. The examination of co-occurring hashtag graphs is important in the analysis of cultural production because it allows the researcher to determine what hashtags were used in conjunction with movement key terms and phrases. Various centrality and other social network analysis measures represent measures of importance of each hashtag to that particular network. Examination of what languages and phrases are used in conjunction with key movement hashtags reveals that as the MSF and related campaign evolved, it began to engage in conversation and interact with transnational actors and feminist movements. While the movement gained international support early on in countries like France and Germany, around 
2018-2019 members began referencing and being referenced by similar women's movements in Latin America and other parts of the world.

\section{My Stealthy Freedom Hashtag Graphs}

A common approach to using social network analysis (SNA) to examine social media data is to map retweet or friend networks where the nodes are users and the links are retweets or followers. While this approach can be useful to examine the behavior of online groups, mapping of the user networks did not provide more information than was already know through content analysis and interviews. To dig deeper into the content using network analysis, co-occurring hashtag graphs were created in order examine which hashtags are being used simultaneously and how (if at all) these related movements overlap.

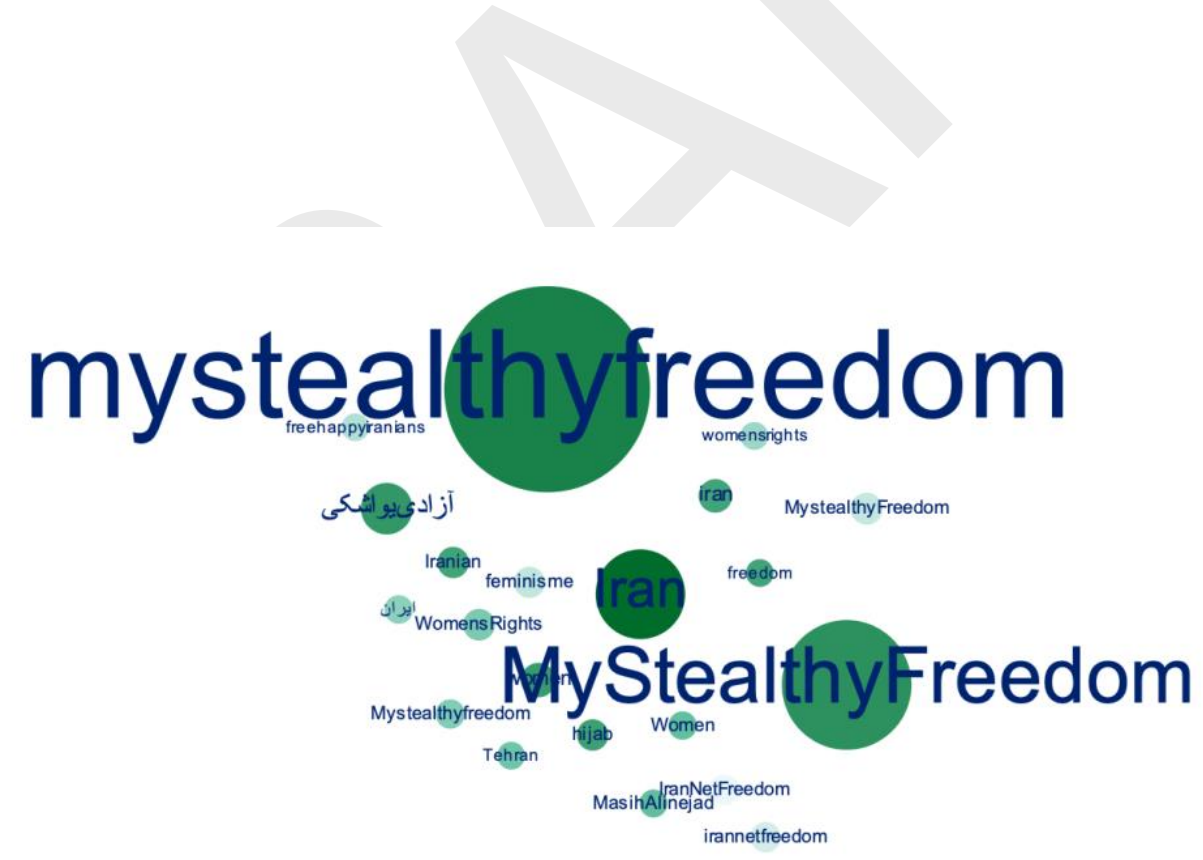

Figure 10 - MSF 2014-2015 Co-Occurring Hashtag Graph

Figure 10 shows a co-occurring hashtag graph of the MSF 2014-2015 tweets where the size and label of each node represents number of co-occurrence and the coloring of the node represented Eigen Vector Centrality. In the MSF 2014-2015 Co-Occurring Hashtag Graph, hashtags with the 
highest Eigen Vector Centrality (EVC) are hijab (0.920), Women (0.912) and WomensRights (0.821). This demonstrates the interests of movement members who use \#MyStealthyFreedom along with hashtags representing their other issues or causes such as the hijab, women and women's rights. While these results are expected (it makes sense that a women's rights campaign would use terms related to women and women's rights), these innovative methodologies allow researchers to use empirical evidence to confirm descriptive observations of social networks.

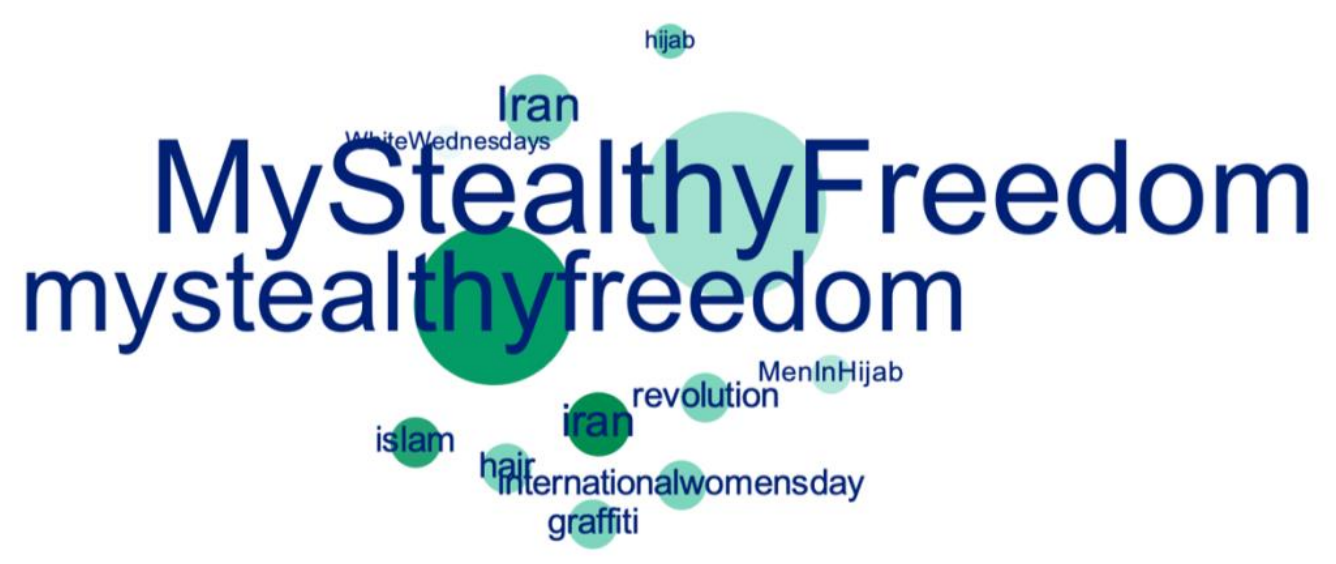

Figure 11 - MSF 2016-2017 Co-Occurring Hashtag Graph 


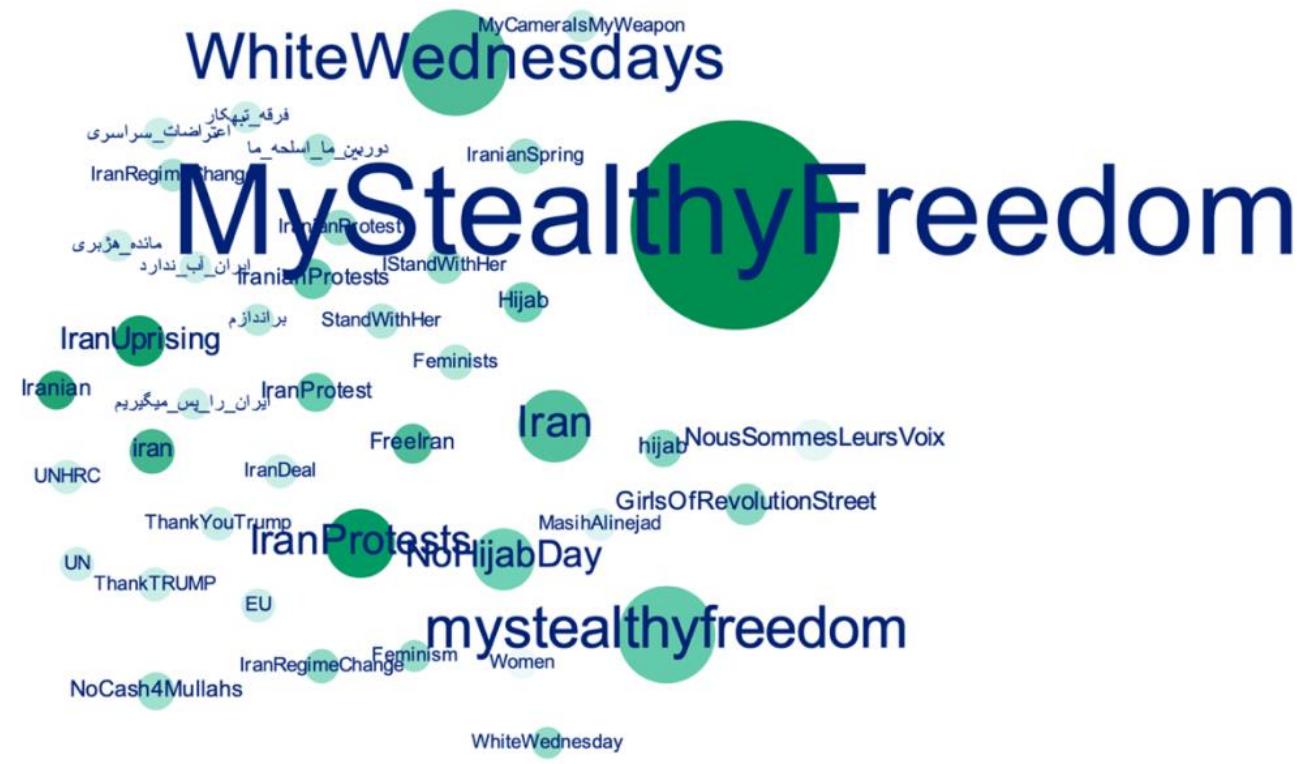

Figure 12 - MSF 2018 Co-Occurring Hashtag Graphs

The above co-occurring hashtag graphs of MSF 2016-2017 (Figure 11) and 2018 (Figure 12) show that users consistently post content related to Iran and women's issues. In contrast, the hashtag graphs of the movement from 2019 in Figure 13 show several more international and transnational connections with the MSF and related movements. 


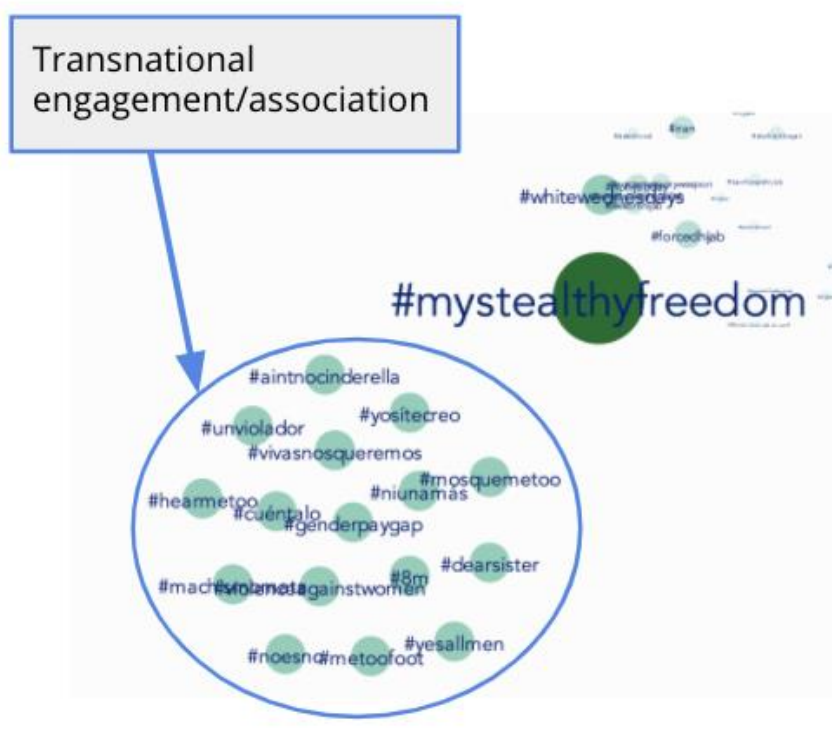

Figure 13 - MSF 2019 Network Graphs

Examination of the hashtag graph for MSF 2019 shows that the movement continues to interact heavily with related digital campaigns discussed here such as WW and MCW as well as several transnational feminist movements, represented by the large light green nodes in the bottom left corner of Figure 31. While this cross-movement interaction is expected since the movement began as MSF and evolved to use related hashtags, the fragmented clusters on the left and the large network at the top right show new networks that begin to co-reference and become associated with the original movement through co-occurring hashtags. For example, many of the terms from the subnetwork circled in blue are in Spanish, showing how the MSF campaign has forged transnational relationships with women's movements in Central and Latin America.

One related hashtag, \#AintNoCinderella, is a campaign to fight victim blaming in India after a member of the Bharatiya Janata Party's (BJP) sons was accused of stalking a local radio DJ, Varnika Kundu. The party's vice president, Ramveer Bhatti, responded by saying Varnika should not have been out so late. Indian women reacted by criticizing these regressive responses 
and posting pictures of themselves at midnight, claiming that there should be no restrictions on women in public space and proving that they are not Cinderella.xviii

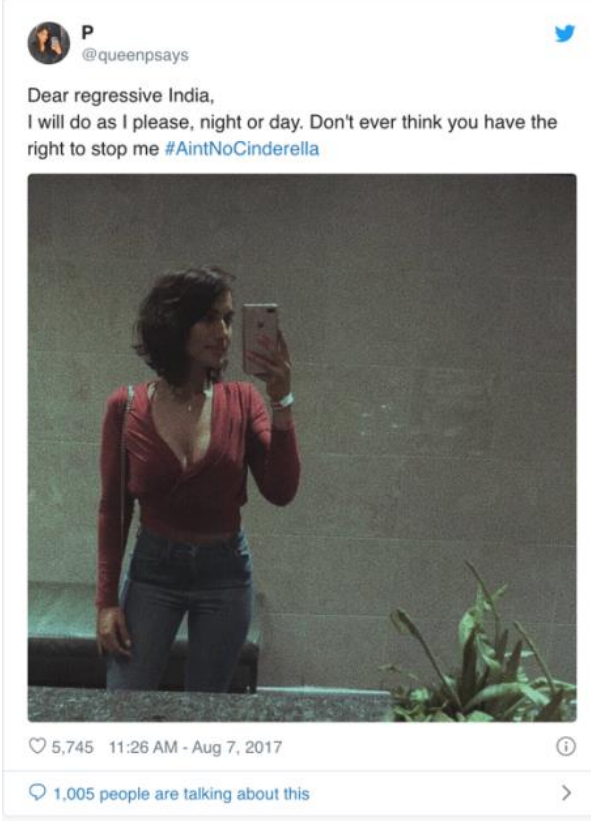

Figure 14 - \#IAintNoCinderella

As often happens with cultural production by social movements, popular celebrities and public figures also participate in these memes, facilitating wide-spread transnational dissemination. The tweet below by Palak Sharma, a famous Indian actress, gained over 4,000 retweets, demonstrating the impact celebrity endorsement can have on audience attention and engagement (Figure 15).xix 


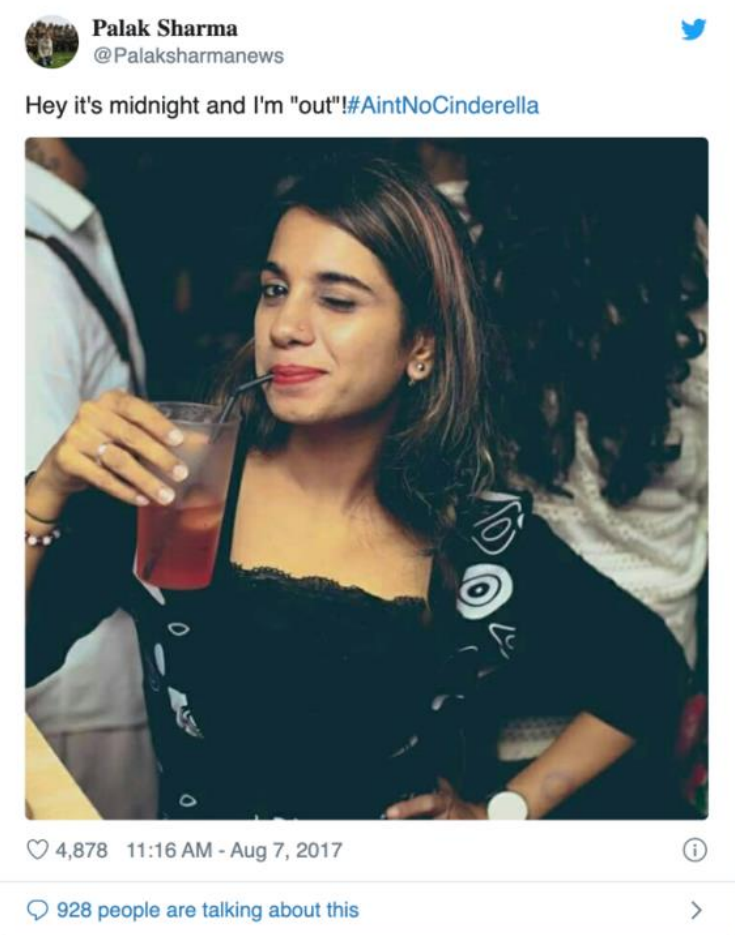

Figure 15 - \#IAintNoCinderella

Figure 16 depicts Mexican feminists call for action against femicide and the increased violence against women in the country and the region since the 1990s through hashtags like \#MiUnaMas (Not One More). The campaign organizes protests such as the one depicted below. The protests followed the killing of two young women in January and February 2020 - Isabel Cabanillas de la Torre and Ingrid Escamilla. Both were murdered in Ciudad Juarez and Mexico City within two weeks, sparking outrage on social media. Cabanillas was a women's rights activist and artist part of a collective, Hijas de su Maquilera Madre, which defends women's rights, ecofeminism and gender equality. Cabanillas was reported missing on January 18 by her friends after she did not return to her home after a night out and was later found shot dead in Ciudad Juárez, Chihuahua. In response, people protested and marched in cities across Mexico, 
calling for justice and the attention of the Mexican government to the epidemic of gender-based violence.xx

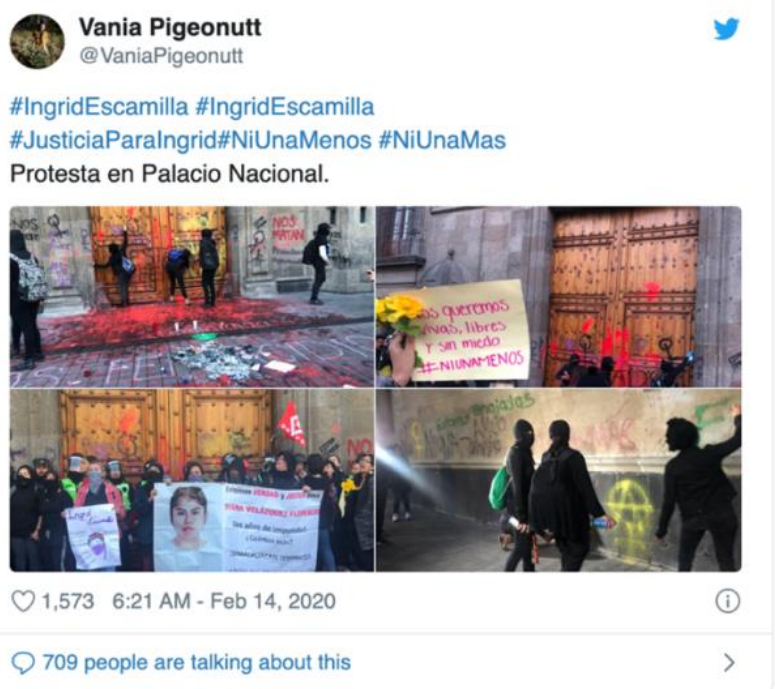

Figure 16- \#NiUnaMas February 2020

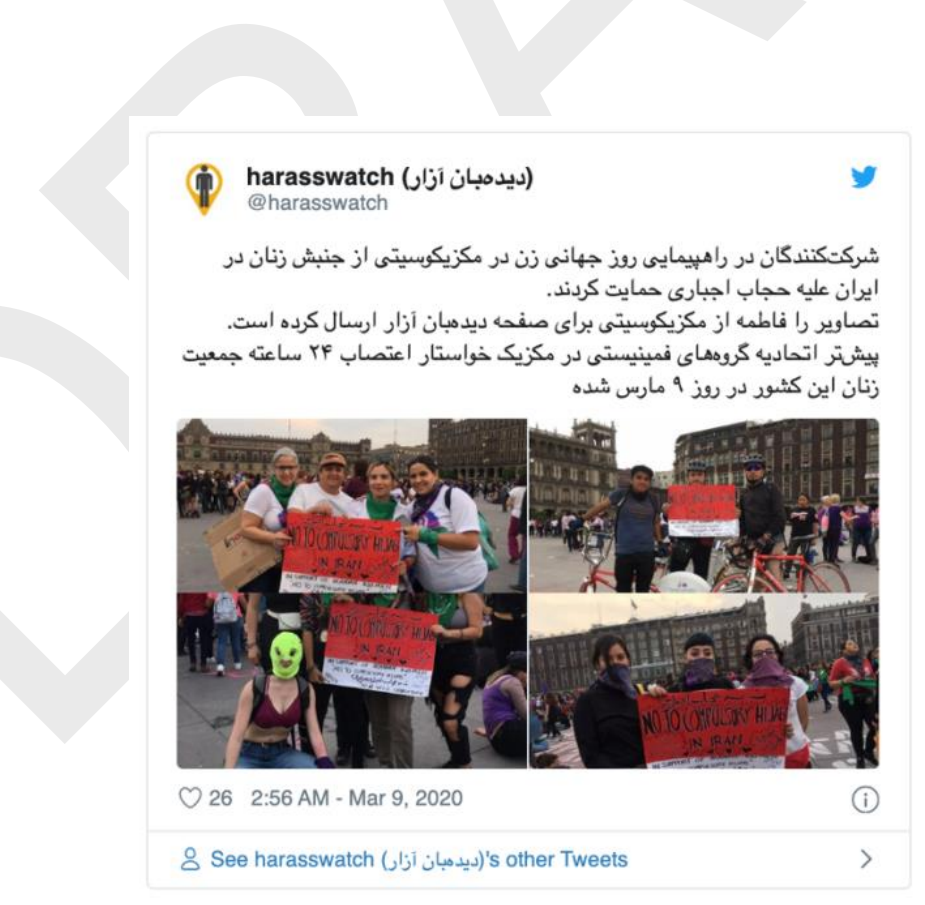

Figure 17 - Harass Watch Protests 
Organizations such as Harass Watch help spread the movement's message and encourage transnational participation.xxi The image above was taken in Mexico on March 5th, 2020 and shows protestors holding signs to challenge compulsory hijab for women in Iran. The tweet text translates to: "Participants in the International Women's Day march in Mexico City supported the women's movement in Iran against forced veil. Images were sent by Fatima from Mexico City to the Harass Watch page. Earlier, feminist groups in Mexico call for a two-hour strike on March 5".xxii

Other related campaigns using co-hashtags with MSF include those from activists in Saudi Arabia, including \#IAmMyOwnGuardian (Figure 18) where over 15,000 Saudi women signed an online petition to demand that the country abolish its male guardianship system which requires women to obtain the consent of a man on major decisions such as travelling, getting married or working.xxiii

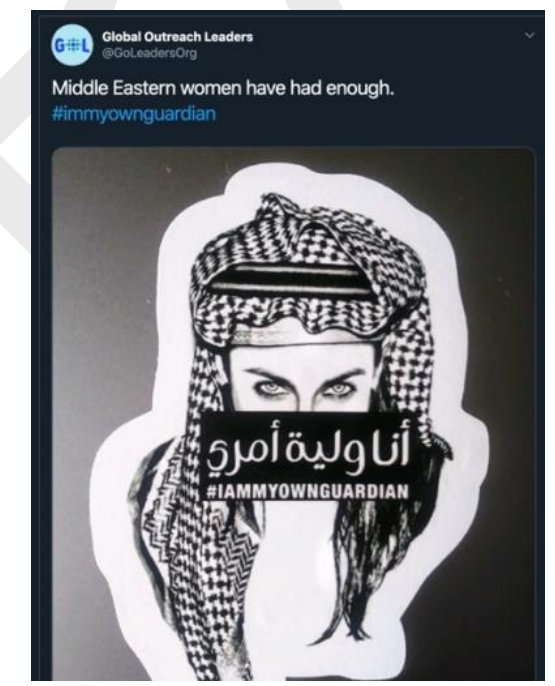

Figure 18 - \#IAmMyOwnGuardian 
As seen through the above examples, the use of mobile phone cameras and the ability to curate presentations of self online have become ways for women to assert their rights to public space and expression. The MSF campaign evolved from the idea of stealthy freedom to a movement with more explicit symbols of protest with White Wednesdays in 2017 and finally to My Camera Is My Weapon.

\section{Publishers to Platforms: Social Media as Data}

The cases of media activism addressed in this paper aimed to explain the potentials of using social media as data to examine social movements and other socio-political phenomena. The analysis of Twitter co-occurring hashtag graphs reveals the network structures of transnational movements that use social media technologies to disseminate their messages, even under repressive regimes. The subtle protest and resistance practiced by these nonviolent nonmovements show that particular types of content gain more audience attention and engagement on these platforms. While it was already known that images tend to gain more attention, the data presented here provides empirical evidence that this is often, but not always, true. Perhaps most exciting, while it was known that social movements communicate and learn cross-nationally from other movements, the co-occurring hashtag graphs provide empirical evidence of this transnational connection where women's and feminist movements in all regions of the world communicate cross-nationally and learn together about the strengths and weaknesses of using social media and other technology to promote human rights and social justice.

While formal US-Iranian relations continue to struggle under Trump's maximum pressure campaign, the informal connections formed between citizens and civil societies of both countries continues to flourish with the help of advancements in technology and communication. At the 
same time, media outlets and social media influencers, including politicians, construct and disseminate mis- and disinformation that corrupts public knowledge and confuses or distracts users, leading to a new era of disenchantment, media exhaustion, and polarization.

\section{Future of Technology and Policy Recommendations}

Advances in information technology (IT) and biotechnology have created new policy opportunities and concerns that have drastic implications for both state and non-state actors. With the rise of big data, artificial intelligence, cryptocurrencies and an array of other technological advancements, a main concern for the future of online information sharing and activism is how to keep the exchange of ideas and information on the internet free, open and transparent despite the rising presence of misinformation. While companies like Facebook and Twitter have already started to address these issues by allowing users to flag content that they deem to be misinformation or blocking political ads, more must be done to ensure that similar standards for print journalism are applied to the production and consumption of digital content and to generally hold these platforms accountable. Currently Facebook and other social media platforms are being used to fund terrorism and illicit trade despite efforts to combat this type of activity through regulation and policy reforms.

\section{Corporate Responsibility and Challenges Moving Forward}

While large technology companies such as Facebook and Twitter now serve as the gatekeepers of public information in an era of platforms, the same rules and regulations that once kept publishers accountable unfortunately cannot easily be applied to social media companies. Social media is often used by repressive governments to surveil and censor their populations, but the role and responsibility of social media platforms to prevent these injustices from occurring is just beginning to take shape and is constantly evolving. 
Human rights abuses are difficult to regulate on social media platforms for several reasons. First, they are often not a financial or business issue - problems like human and drug trafficking involve the transaction of illicit funds on platforms, something the companies would prefer to prevent and are willing to spend resources to combat. Second, establishment violence and human rights abuses are often difficult to enforce not only for social media platforms, but also for traditional law enforcement. Critical human rights and social justice cases are often decided through legislation or the judicial system. It is not the place of law enforcement to carry out policy. Given their transnational nature, social media companies like Facebook spend resources researching and preventing explicit criminal activity on their platforms such as human trafficking and terrorism rather than combating state sponsored or establishment violence.

Information technology is not the only field that will shape the future of technology policy and human rights. Advancements in areas such as artificial intelligence (AI) and biotechnology are already influencing state-societal relations. If placed in the wrong hands, these powerful new technologies could signal a further shift of power from civil society activists to repressive authorities and governments.

\section{Artificial Intelligence and Facial Recognition}

The use of artificial intelligence such as machine learning and facial recognition allows authoritarian governments to significantly enhance their security and surveillance capabilities. For example, China's AI and facial recognition technologies Megvii Face++ and Skynet system have been developed to create a vast surveillance state, allowing the government to more easily track down criminals and dissidents. The Face++ platform has been used by Chinese law enforcement to help them arrest 4,000 people, including drug smugglers, with 97 percent accuracy since 2016.xxiv The power of these new surveillance technologies could also be 
harnessed by civil society actors to advance social justice causes. For instance, researchers and technology experts have experimented with facial recognition and sophisticated image processing software to combat human trafficking and other illicit content such as child pornography.xxv These tools are particularly effective because they are able to detect the age and gender of an individual from image or video data. This allows these organizations to target suspicious activity such as an underage person checking into a hotel with an individual known to facilitate human trafficking.

\section{Blockchain Combats Corruption Though Transparent Data}

The establishment of block chain or distributed ledgers may entirely alter the future of traditional banking and financial institutions. But the potential of block chain is not limited to the financial sector. Blockchain can be used to combat government corruption and keep authoritarian governments like that of the IRI more accountable and transparent. Unlike traditional transaction mechanisms where one entity or central authority maintains a track of transactions, data on a blockchain is stored in encrypted blocks that are managed by a decentralized global computer network. Blockchain or non-hierarchical distributed ledgers could be used to combat state corruption or organized crime because their decentralized structure allows for more transparent and trustworthy exchanges. By moving bureaucratic tasks, such as the production of land titles, out of state control, blockchain prevents and combats corruption and the abuse of information by powerful state or business actors.xxvi Decentralizing the tracking of financial and other records would challenge the Iranian government's centralized control and create a window of opportunity for activists and other civil society actors to both identify and combat the IRI's repressive tactics. 
While the previous recommendations are likely to support Iranian online activism, there is also a need for the Iranian human and women's rights movements to be supported by the international community in order to be successful. NGOs and IGOs are useful allies for digital activists, but substantive policy change also requires technological skill and experience as well as the support of large tech companies such as Apple and Google. For example, on August 24, 2018 Apple began removing apps developed by Iranians from its application marketplace. In September 2018 Google followed Apple's lead and also began removing Iranian apps, signaling the damaging impact of U.S. sanctions on the county's online interactions. Despite the Department of Treasury's Office of Foreign Assets Control (OFAC) 2014 General License D-1 which authorized goods and services and other communication tools to be provided to Iranians without risk, tech companies fear that with the reestablishment of U.S. sanctions they may be held liable for apps in their stores written and used by Iranians.xxvii The reluctance of international developers to work in Iran benefits and is therefore encouraged by Iranian officials who have already sought to create an isolated national internet through the country's National Information Network (NIN/SHOMA) project that began in 2005 under the presidency of Mahmoud Ahmadinejad. If successful, this initiative will succeed in blocking the Iranian public from accessing the global Web, restricting domestic traffic to its own national connection. The Islamic regime is engaging in technology innovation to maintain a monopoly over the control of media and information flow into its borders, just as it has done with previous media outlets such as newspapers, radio and television.

Given Iran's repressive internet policies and strict government control of IT and other technology, a final recommendation is for the international community to fight for a free and easily accessible global internet. As seen in the cases of China, North Korea, Russia and Iran, 
governments are already attempting to establish their own separate national internets that enable them to disconnect their populations from the global online community, cutting them off from the source of one of the key strengths of non-movements, the power in numbers. If individual governments succeed in creating sovereign national versions of the internet, much of this technology's potential for positive social change will be lost. 


\section{Appendix - Scatterplots and Initial Models}

\begin{tabular}{|c|c|}
\hline & Model 1 \\
\hline (Intercept) & $\begin{array}{l}20.29 * \\
(9.18)\end{array}$ \\
\hline flesch_reading_ease & $\begin{array}{c}0.21 \\
(0.14)\end{array}$ \\
\hline media_count & $\begin{array}{c}10.46 \\
(11.40)\end{array}$ \\
\hline $\mathrm{R}_{2}$ & 0.00 \\
\hline Adj. $R_{2}$ & 0.00 \\
\hline Num. obs. & 1419 \\
\hline RMSE & 292.65 \\
\hline
\end{tabular}

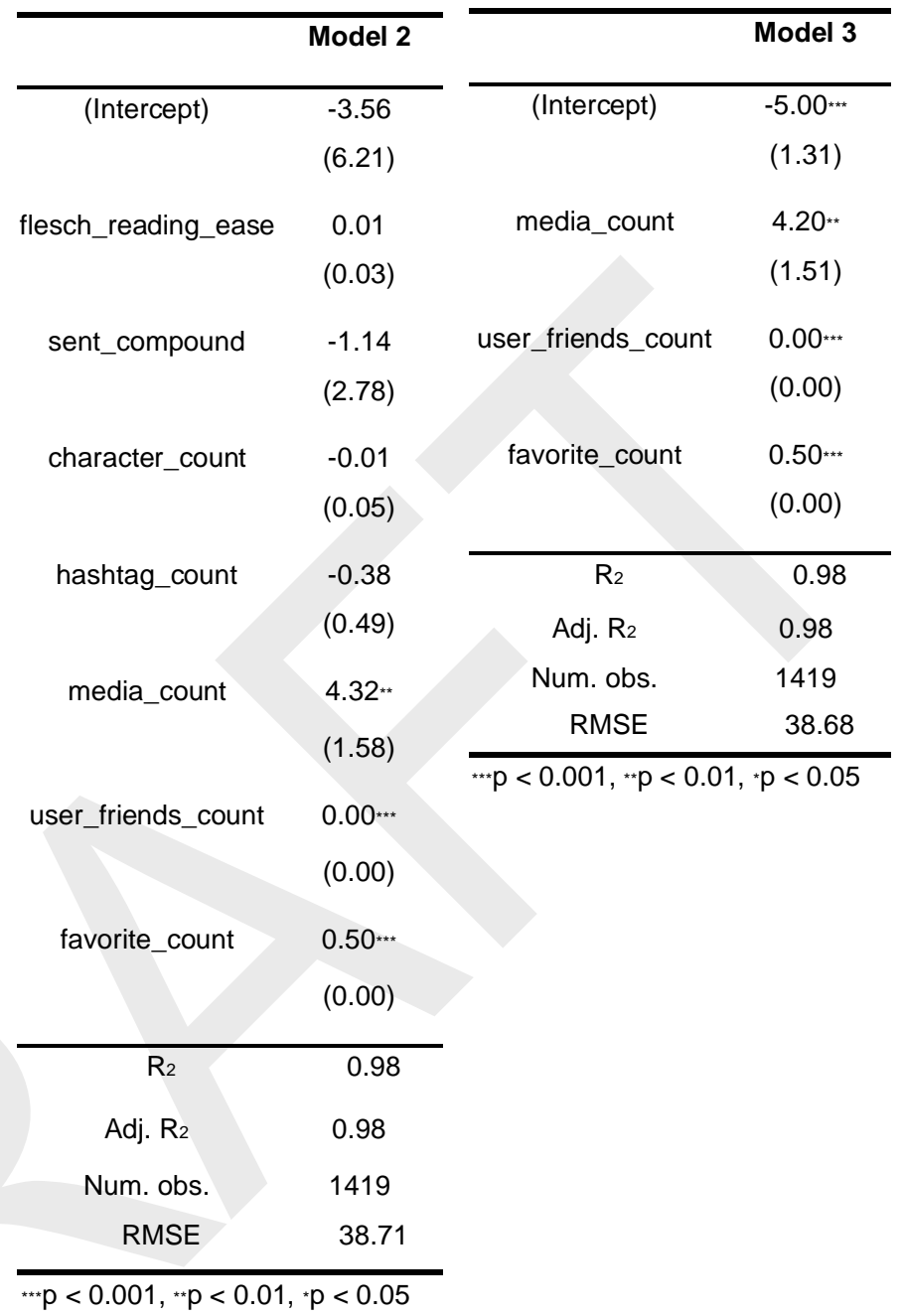

Initial models for the project included variables such as flesch reading ease score and sentimental analysis of the tweet. Because these variables showed no statistical significance and thus added no additional value to the models, they were not used in the final models. 


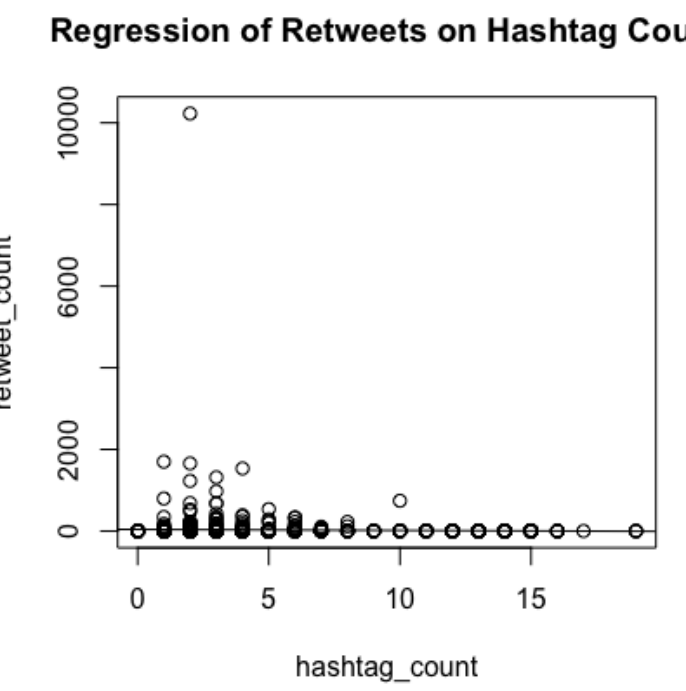

Scatterplot of Hashtag Count and Retweet Count for MSF 2018 


\section{Bibliography}

Bajoghli, Narges. 2019. Iran Reframed: Anxieties of Power in the Islamic Republic. Stanford Studies in Middle Eastern and Islamic Societies and Cultures. Stanford, California: Stanford University Press.

Bayat, Asef. 2007. Making Islam Democratic: Social Movements and the Post-Islamist Turn. Stanford, Calif: Stanford University Press.

- 2013. Life as Politics: How Ordinary People Change the Middle East. Second edition. Stanford, California: Stanford University Press.

Benkler, Yochai. 2011a. "Network Theory | Networks of Power, Degrees of Freedom." International Journal of Communication 5(0): 39.

- 2011b. "Networks of Power, Degrees of Freedom." : 35.

Burger, John D., John Henderson, George Kim, and Guido Zarrella. 2011. "Discriminating Gender on Twitter." In Proceedings of the Conference on Empirical Methods in Natural Language Processing, EMNLP '11, Edinburgh, United Kingdom: Association for Computational Linguistics, 1301-1309.

Christensen, Christian. 2011. "Twitter Revolutions? Addressing Social Media and Dissent." The Communication Review 14 (3): 155-57. https://doi.org/10.1080/10714421.2011.597235.

Dencik, Lina, and Oliver Leistert, eds. 2015. Critical Perspectives on Social Media and Protest: Between Control and Emancipation. New York: Rowman \& Littlefield International.

Goldstone, Jack A. 2004. "More Social Movements or Fewer? Beyond Political Opportunity Structures to Relational Fields." Theory and Society 33(3/4): 333-65.

Goldstone, Jack A., and Daniel P. Ritter. 2018. "Revolution and Social Movements." In The Wiley Blackwell Companion to Social Movements, eds. David A. Snow, Sarah A. Soule, Hanspeter Kriesi, and Holly J. McCammon. Chichester, UK: John Wiley \& Sons, Ltd, 68297. http://doi.wiley.com/10.1002/9781119168577.ch39 (April 9, 2019).

Hippel, Eric von, and Eric von Hippel. 2006. Democratizing Innovation. 1. MIT Press paperback ed. Cambridge, Mass.: MIT Press.

Jumet, Kira D. 2018. Contesting the Repressive State: Why Ordinary Egyptians Protested during the Arab Spring. New York, NY: Oxford University Press.

Kellner, Douglas. 2014. "Habermas, the Public Sphere, and Democracy." In Re-Imagining Public Space, eds. Diana Boros and James M. Glass. New York: Palgrave Macmillan US, 19-43. http://link.springer.com/10.1057/9781137373311_2 (May 26, 2018).

Kidd, Dustin, and Keith McIntosh. 2016. "Social Media and Social Movements: Social Media and Social Movements." Sociology Compass 10(9): 785-94.

Koopmans, Ruud. 2004. "Movements and Media: Selection Processes and Evolutionary Dynamics in the Public Sphere." Theory and Society 33(3/4): 367-91.

Loudon, Melissa, and B. Theo Mazumdar. 2013. "Media Representations of Technology in Egypt's 2011 pro-Democracy Protests.” Ecquid Novi: African Journalism Studies 34(1): $50-67$.

Malone, Thomas W., and Michael S. Bernstein, eds. 2015. Handbook of Collective Intelligence. Cambridge, Massachusetts: MIT Press.

Marwick, Alice E., and danah boyd. 2011. "I Tweet Honestly, I Tweet Passionately: Twitter Users, Context Collapse, and the Imagined Audience." New Media \& Society 13(1): 114-33. 
McAdam, Doug, Sidney G. Tarrow, and Charles Tilly. 2001. Dynamics of Contention.

Cambridge; New York: Cambridge University Press.

Mind, An Xian. 2019. Memes to Movements: How the World's Most Viral Media Is Changing Social Protest and Power. Boston: Beacon Press.

Qi, Jiayin, Emmanuel Monod, Binxing Fang, and Shichang Deng. 2018. "Theories of Social Media: Philosophical Foundations.” Engineering 4(1): 94-102.

Rodgers, Jayne. 2003. Spatializing International Politics: Analysing Activism on the Internet.

London; New York: Routledge.

Sreberny, Annabelle, and Massoumeh Torfeh, eds. 2016. Cultural Revolution in Iran:

Contemporary Popular Culture in the Islamic Republic. London New York: Tauris.

Tufekci, Zeynep. 2017. Twitter and Tear Gas: The Power and Fragility of Networked Protest.

New Haven London: Yale University Press.

Wilson, Steven Lloyd. 2017. "Information and Revolution." SSRN Electronic Journal. https://doi.org/10.2139/ssrn.2984819.

57 


\section{References}

i World Bank. "Broadband Networks in the Middle East and North Africa: Accelerating HighSpeed Internet Access." Text/HTML. Accessed November 22, 2019. https://www.worldbank.org/en/region/mena/publication/broadband-networks-in-mna ii Benkler, Yochai. "Network Theory | Networks of Power, Degrees of Freedom." International Journal of Communication, vol. 5, no. 0, Apr. 2011, p. 39.

iii Malone, Thomas W., and Michael S. Bernstein, editors. Handbook of Collective Intelligence. MIT Press, 2015.

MIT Communications Forum. OVS | Media in Transition 5: Collaboration and Collective Intelligence. https://techtv.mit.edu/videos/16231-media-in-transition-5-collaboration-andcollective-intelligence-mit-communications-forum. Accessed 23 Oct. 2018.

iv Benkler, Yochai. Networks of Power, Degrees of Freedom. 2011, v Rich, Frank. 2011. "Opinion | Wallflowers at the Revolution." The New York Times, February 5, 2011, sec. Opinion. https://www.nytimes.com/2011/02/06/opinion/06rich.html. vi Loudon, Melissa, and B. Theo Mazumdar. 2013. "Media Representations of Technology in Egypt's 2011 pro-Democracy Protests.” Ecquid Novi: African Journalism Studies 34 (1): 50-67. https://doi.org/10.1080/02560054.2013.767424. vii Unititled, from the series, "Witness 1979”, Arthur M. Sackler Gallery https://asia.si.edu/object/S2015.21/ viii McDonell, Stephen. 2019. "WeChat and the Surveillance State." BBC News, June 7, 2019, sec. China blog. https://www.bbc.com/news/blogs-china-blog-48552907.

ix Ma, Alexandra. n.d. "China Has Started Ranking Citizens with a Creepy 'social Credit' System - Here's What You Can Do Wrong, and the Embarrassing, Demeaning Ways They Can Punish You." Business Insider. Accessed April 11, 2020. https://www.businessinsider.com/china-socialcredit-system-punishments-and-rewards-explained-2018-4.

x Charlie Campbell. 2019. "The Entire System Is Designed to Suppress Us': What the Chinese Surveillance State Means for the Rest of the World.” Time. November 21, 2019. https://time.com/5735411/china-surveillance-privacy-issues/.

xi Kidd, Dustin, and Keith McIntosh. 2016. "Social Media and Social Movements: Social Media and Social Movements." Sociology Compass 10(9): 785-94.

xii Bajoghli, Narges. 2019. Iran Reframed: Anxieties of Power in the Islamic Republic. Stanford Studies in Middle Eastern and Islamic Societies and Cultures. Stanford, California: Stanford University Press.

xiii Sreberny, Annabelle, and Massoumeh Torfeh, eds. 2016. Cultural Revolution in Iran: Contemporary Popular Culture in the Islamic Republic. London New York: Tauris. xiv Allison Lips. 2018. "History of Hashtags: How a Symbol Changed the Way We Search \& Share." Social Media Week. https://socialmediaweek.org/blog/2018/02/history-hashtags-symbolchanged-way-search-sharel (March 2, 2020).

xv Cathrine Shu. 2012. "Twitter Mobile Now Available In Arabic And Farsi.” Tech Crunch. December 11, 2012. https://techcrunch.com/2012/12/11/twitter-mobile-now-available-in-arabicand-farsil. xvi "People Infected With HIV In A Region Of Iran Attack Government Buildings." n.d. RFE/RL. Accessed December 3, 2019. https://en.radiofarda.com/a/people-infected-with-hiv-in-aregion-of-iran-attack-government-buildings/30200938.html. 
xvii "Protesting Workers Battered By Security Forces In Iran." n.d. RFE/RL. Accessed December 3, 2019. https://en.radiofarda.com/a/protesting-workers-battered-by-security-forces-iniran/30169043.html. xviii McNamara, Brittney. "Women in India Are Posting Late-Night Selfies For an IMPORTANT Reason.” Teen Vogue. https://www.teenvogue.com/story/women-india-aint-no-cinderellahashtag-victim-blaming (February 26, 2020).

xix Livsey, Anna. 2017. “\#AintNoCinderella: Indian Women Mock Politician Who Blamed Stalking Victim." The Guardian, August 9, 2017, sec. World news.

https://www.theguardian.com/world/2017/aug/09/aintnocinderella-indian-women-mockpolitician-who-blamed-stalking-victim.

xx Michael Herrera. 2020. "\#NiUnaMas: Mexican Feminists Are Renewing Their Calls for Action Against Femicide - Ms. Magazine.” MS Magazine. https://msmagazine.com/2020/02/21/mexico-femicide/ (February 26, 2020). xxi “مقابله با آزار جنسى در فضاى عمومى." ه.d. Aرس واتج | ديدهبان آزار. Accessed May 6, 2020. https://harasswatch.com/.

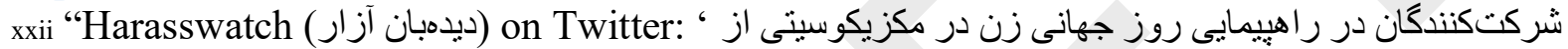

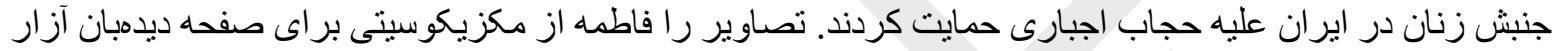

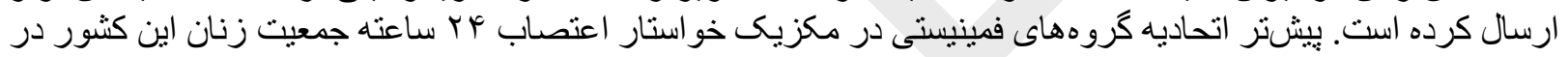
.Https://T.Co/0547o7hx3s' / Twitter.” n.d. Twitter. Accessed May 6, 2020. https://twitter.com/harasswatch/status/1236954046281461761?ref_url=https\%3a\%2f\%2fpublish. twitter.com $\% 2 \mathrm{f} \% 3$ fquery $\% 3 \mathrm{dhttps} \% 253 \mathrm{a} \% 252 \mathrm{f} \% 252 \mathrm{ftwitter} . \mathrm{com} \% 252 \mathrm{fharass} w a t c h \% 252 \mathrm{fstatu}$ s\%252f1236954046281461761\%26widget\%3dtweet.

xxiii Mangla, Ismat Sarah. n.d. "\#IAmMyOwnGuardian: Thousands of Saudi Women Petition for the Right to Make Decisions without a Man's Permission." Quartz. Accessed April 14, 2020. https://qz.com/793285/saudi-women-petition-to-end-male-guardianship-system-followingonline-campaign/.

xxiv Jacobs, Harrison. “China's ‘Big Brother' Surveillance Technology Isn’t Nearly as All-Seeing as the Government Wants You to Think." Business Insider, https://www. businessinsider.com/china-facial-recognition-limitations-2018-7. Accessed 24 Oct. 2018. xxv Wakefield, Jane. AI Lawyer Predicts Outcome of Cases. 23 Oct. 2016. www.bbc.com, https://www.bbc.com/news/technology-37727387. xxvi Stephen Demeulenare. "Blockchain Can Be Used to Fight Corruption, Increase Transparency in Govt Projects- Technology News, Firstpost.” Tech2, 10:09:41 +05:30, https://www.firstpost.com/tech/news-analysis/blockchain-can-be-used-to-fight-corruptionincrease-transparency-in-govt-projects-4664681.html.

xxvii Oliver, Danny O'Brien, and Lindsay Oliver. "Iranian Hardliners Want An Isolated Internet — US Politicians and Companies Shouldn't Help.” Electronic Frontier Foundation, 13 Oct. 2017, https:/www.eff.org/deeplinks/2017/10/iranian-hardliners-want-isolated-internet. 


\section{BIOGRAPHY}

Layla M. Hashemi is a Policy PhD Candidate at George Mason University's Schar School and a graduate research assistant at George Mason University's Terrorism, Transnational Crime and Corruption Center (TraCCC). Ms. Hashemi received her M.A. from New York University in International Relations and Middle Eastern and Islamic Studies. Ms. Hashemi has worked for various organizations including Forum 2000 and The Journal of Civil Society. She is currently an adjunct professor of Political Science at Montgomery College where she teaches a variety of courses including Comparative Politics, International Conflict Resolution and a course she helped develop on Global Human Rights. Her current research focuses on illicit trade, human trafficking and corruption in the Middle East and North Africa (MENA). 